Key words: pinniped, harbour seal, vocal anatomy, acoustic allometry, trachea, larynx, vocal tract

\section{VOCAL TRACT ALLOMETRY IN A MAMMALIAN VOCAL LEARNER}

\author{
Koen de Reus ${ }^{1,2,3^{* \#}}$, Daryll Carlson ${ }^{3,4}$, Alice Lowry 3,5 , Stephanie Gross 6 , Maxime Garcia ${ }^{7,8}$, Ana \\ Rubio-Garcia ${ }^{3}$, Anna Salazar-Casals ${ }^{3}$, Andrea Ravignani ${ }^{1,3 \#}$ \\ ${ }^{1}$ Comparative Bioacoustics Group, Max Planck Institute for Psycholinguistics, Nijmegen, the Netherlands \\ ${ }^{2}$ Artificial Intelligence Lab, Vrije Universiteit Brussel, Brussels, Belgium \\ ${ }^{3}$ Research Department, Sealcentre Pieterburen, Pieterburen, the Netherlands \\ ${ }^{4}$ Department of Earth System Science, Stanford University, Stanford, USA \\ ${ }^{5}$ School of Environmental Sciences, University of Liverpool, Liverpool, United Kingdom \\ ${ }^{6}$ Institute for Terrestrial and Aquatic Wildlife Research (ITAW), University of \\ Veterinary Medicine Hannover, Foundation, Büsum, Germany \\ ${ }^{7}$ Animal Behaviour, Department of Evolutionary Biology and Environmental Studies, University of Zurich, Zürich, \\ Switzerland \\ ${ }^{8}$ Center for the Interdisciplinary Study of Language Evolution, University of Zurich, Zürich, Switzerland \\ * These authors share joint first authorship. \\ ${ }^{\#}$ Corresponding Authors: koen.de.reus@ vub.be; andrea.ravignani@ mpi.nl
}

\begin{abstract}
$\underline{\text { Abstract }}$
Acoustic allometry occurs when features of animal vocalisations can be predicted from body size measurements. Despite this being considered the norm, allometry sometimes breaks, resulting in species sounding smaller or larger than expected. A recent hypothesis suggests that allometry-breaking animals cluster into two groups: those with anatomical adaptations to their vocal tracts and those capable of learning new sounds (vocal learners). Here we test this hypothesis by probing vocal tract allometry in a proven mammalian vocal learner, the harbour seal (Phoca vitulina). We test whether vocal tract structures and body size scale allometrically in 68 individuals. We find that both body length and body weight accurately predict vocal tract length and one tracheal dimension. Independently, body length predicts vocal fold length while body weight predicts a second tracheal dimension. All vocal tract measures are larger in weaners than in pups and some structures are sexually dimorphic within age classes. We conclude that harbour seals do comply with allometric constraints, lending support to our hypothesis.
\end{abstract} However, allometry between body size and vocal fold length seems to emerge after puppyhood, suggesting that ontogeny may modulate the anatomy-learning distinction previously hypothesised as clear-cut. Species capable of producing non-allometric signals while their vocal tract scales allometrically, like seals, may then use non-morphological allometry-breaking mechanisms. We suggest that seals, and potentially other vocal learning mammals, may achieve allometry-breaking through developed neural control over their vocal organs. 


\section{Introduction}

43 In many species, acoustic signals help mediate social interactions among individuals such as competition

44 for mates and territory, and parent-offspring recognition (Bradbury \& Vehrencamp, 1998; Martin, Tucker,

$45 \&$ Rogers, 2017). Signals can encode information about the caller's biology which can be readily

46 deciphered by the receiver, including age (Reby \& McComb, 2003; Charlton, Zhihe, \& Snyder, 2009), sex (Vignal \& Kelley, 2007; Charlton et al., 2009), body size (Fitch, 1997; Charlton et al., 2009; Charlton et al., 2011, Garcia, Wondrak, Huber, \& Fitch, 2016), hormone levels (Koren \& Geffen, 2009), and physical condition (Wyman, Mooring, McCowan, Penedo, \& Hart, 2008; Koren \& Geffen, 2009).

In particular, body size often shapes mammalian sounds by constraining the geometry of the vocal tract (Fitch, 2000; Reby \& McComb, 2003). Acoustic cues relating to the body size of the caller can inform the receiver about the caller's competitive ability and reproductive success (Poole, 1999; Reby \& McComb, 2003; Kuester, Paul, \& Arnemann, 1995; Pfefferle \& Fischer, 2006). For example, in primates and carnivores, there is an inverse relationship between body size and the call frequency parameters, where larger animals produce calls with lower frequencies, i.e., have a 'deeper' voice (Bowling et al., 2017). This relationship between acoustical call features and their accurate reflection of body size is known as 'acoustic allometry' (Taylor \& Reby, 2010; Fitch, 1997). Here, signalling is considered honest when the acoustic parameters of observed vocalisations accurately reflect an individual's body size (Fitch \& Hauser, 2003). Deviations from allometry can generate dishonest signals, with animals sounding unexpectedly small or large for their body size (Garcia \& Ravignani, 2020). Dishonest signals may be produced when an animal has a non-allometric vocal tract, or enhanced control over their vocal organs which allows them to learn or modify existing vocalisations: an ability known as 'vocal learning'. Recent cross-species work indeed showed that, given a cross-species regression between sounds produced and body size, outlier species seem to cluster either on one side of the line - those with anatomical adaptations - or on the other - the vocal learners. This led to a morphology vs. learning hypothesis (Garcia \&

67 Ravignani, 2020; Ravignani \& Garcia, 2021): dishonest signals in mammals may arise either from

68 anatomical adaptations or vocal learning capacities. This prediction has the potential to identify new vocal

69 learners or species with unexpected vocal tract morphology. Vocal learners should therefore violate

70 acoustic allometry while possessing an allometric vocal tract. For the first time, we test this prediction,

71 asking whether vocal tract allometry or a deviation thereof occurs in a vocal learning species which is

72 known to violate acoustic allometry. We do this in harbour seals, a pinniped rapidly becoming a model

73 species for studying mammalian vocal learning. 
75 Pinnipeds are a group of semi-aquatic mammals, with many species exhibiting marked vocal flexibility

76 (Bowen, 1991; Ravignani et al., 2016). Harbour seals are among the few pinnipeds showing vocal

77 learning abilities (Bjørge, Desportes, Waring, \& Rosing-Asvid, 2010; Ralls, Fiorelli, \& Gish, 1985;

78 Borda, Jadoul, Rasilo, Salazar-Casals, \& Ravignani, 2021). They are particularly vocal during the first

79 few weeks following birth (Perry \& Renouf, 1988). Harbour seal pups produce individually distinctive

80 mother attraction calls (Renouf, 1984) which vary with age, sex, and body length (Khan, Markowitz, \&

81 McCowan, 2006; Sauvé, Beauplet, Hammill, \& Charrier, 2015). After weaning, however, these calls

82 disappear entirely from their vocal repertoire, with most vocalisations ceasing aside from occasional

83 clicks and growls (Renouf, 1984). During adulthood, female harbour seals remain almost entirely vocally

84 inactive (Van Parijs \& Kovacs, 2002), but males start vocalising again, producing underwater calls during

85 the mating season (Hanggi \& Schusterman, 1994). The large variation in vocal repertoire observed across

86 individuals, sexes, and age classes makes harbour seals ideal candidates to test the morphology vs.

87 learning hypothesis, i.e., whether a vocal learning mammal does indeed escape acoustic allometry via

88 learning instead of via anatomical adaptations.

90 Most mammalian vocalizations are described via the source-filter theory of vocal production. Within this

91 framework, vocal signals are initially produced by a source and are then filtered by the vocal tract before

92 being released into the environment (Fant, 1970). In mammals, the source of sound production is the

93 larynx, and the filter is composed of the cavities making up the supralaryngeal vocal tract (Fant, 1970)

94 (see Figure 1A). The vocal folds in the larynx are shelves of tissue lying across the airway that attach

95 ventrally and laterally to the thyroid cartilage and dorsally to the arytenoid cartilage (see Figure 1B).

96 When vocalising, the air expelled from the lungs rushes between the vocal folds, causing vibration of

97 their edges and producing sound (Reidenberg \& Laitman, 2010). The sound then continues to propagate

98 along the supralaryngeal vocal tract, being filtered by its geometry, and is finally released as vocalisation.

99 The source-filter framework highlights which vocal tract structures determine specific features present in

100 acoustic signals. The rate of vibration of the vocal folds determines the fundamental frequency (F0) and

101 the cavities of the vocal tract determine formant frequencies (Taylor \& Reby, 2010). Measurements of

102 these vocal tract structures can thus be used to estimate the acoustic features of vocalisations. 
bioRxiv preprint doi: https://doi.org/10.1101/2021.10.29.466455; this version posted November 5, 2021. The copyright holder for this preprint (which was not certified by peer review) is the author/funder, who has granted bioRxiv a license to display the preprint in perpetuity. It is made available under aCC-BY-NC 4.0 International license.
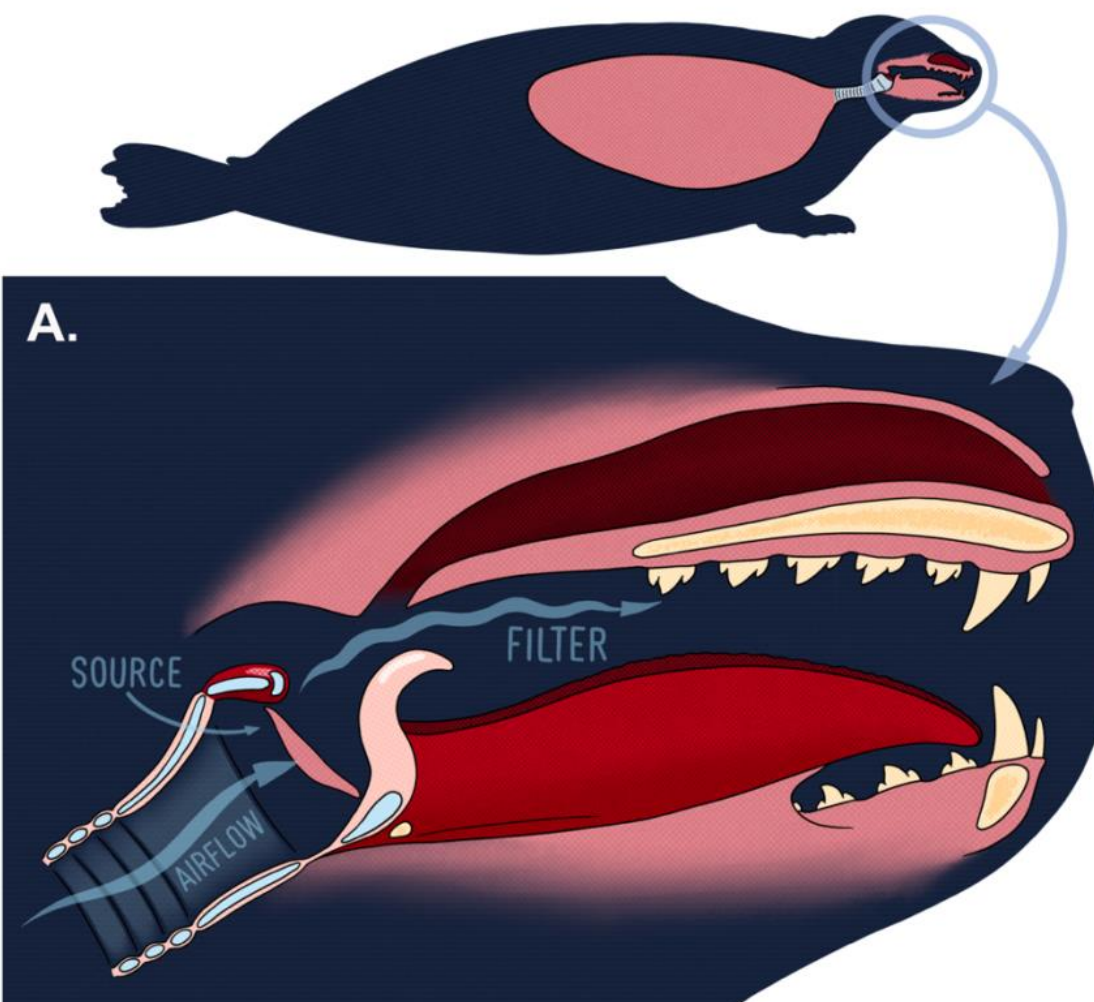
Bioacoustics studies often investigate allometric relationships between acoustic signal features and body size, without consideration of the underlying allometric scaling between body size and vocal anatomy. Mammals often show allometry between body size and upper vocal tract length because the upper vocal tract is constrained by bony structures (Fitch, 1997; Fitch \& Giedd, 1999; Fitch, 2000; Plotsky, Rendall, Riede, \& Chase, 2013; Garcia et al., 2016). However, allometry between body size and the size of the vocal folds is less common: the larynx is surrounded by cartilaginous structures and is thus less constrained, suggesting that vocal fold length can be decoupled from overall body size, as found in nonhuman primates (Fitch \& Hauser, 1995; Fitch, 1997; Garcia, Herbst, Bowling, Dunn, \& Fitch, 2017). In mammals, formants, the acoustic proxy of vocal tract length, are thus a stronger body size predictor than F0, the acoustic proxy of vocal fold length (Fitch, 1997; Garcia et al., 2016). These findings indicate that, if animals do not have particular anatomical adaptations, their upper vocal tract should scale with body size, but their vocal folds should not.

Within the larger framework of the hypothesis above, this study tests for allometric relationships between body size and vocal anatomy measurements in young harbour seals and tests how these relationships vary with sex and age. Preliminary work found that harbour seals' body length correlates with upper vocal tract length and tracheal diameter, but not with vocal fold length (Ravignani et al., 2017). Here, we aim to expand on these findings by using a larger sample size (353\% increase), adding refined anatomical measurements, and comparing different age classes (to test for developmental effects). Based on previous literature, we expect to find allometry between body size and vocal tract structures that are surrounded and hence constrained - by bony structures, such as vocal tract length. However, based on harbour seals' vocal learning abilities (Janik \& Slater, 1997), we expect their vocal flexibility to offer favourable grounds to find deviations from body size allometry for vocal tract components surrounded by cartilage, such as the trachea and vocal fold length.

\section{Materials and methods}

136 Sample collection

137 Larynges were collected during necropsies on 68 harbour seals ( 35 males). 52 samples came from seals 138 that stranded on the Dutch coastline, the rest from animals found on the German coastline (Schleswig139 Holstein). Forty-two animals died in captivity at Sealcentre Pieterburen, Pieterburen, the Netherlands, 140 either naturally during rehabilitation or by means of euthanasia, and 26 animals died in the wild, either 141 naturally or by means of mercy killing (see Table 1 of the Supplement). No animals were harmed for the 142 purpose of this study. 
144 At the time of death, the seals studied were aged between 9 days and 12 months (median 6 months). The

145 age of new-born individuals was estimated in number of days by expert seal veterinarians based on the

146 condition of the umbilical cord or the umbilicus. Older individuals with a closed umbilicus were assigned

147 June as their birth month, which is consistent with the majority of harbour seal births in the Wadden Sea

148 (Osinga, Nussbaum, Brakefield, \& de Haes, 2012; Reijnders, Brasseur, \& Meesters, 2010). Animals aged

1491 month or younger were classified as pups, while those between 1 and 12 months in age were classified

150 as weaners, making age a binary variable. Of the 68 individuals included in this study, 14 (8 males) were

151 classified as pups and 54 (26 males) were classified as weaners. A Fisher's exact test showed no

152 significant associations between age and $\operatorname{sex}\left(\chi^{2}=0.7652, p>.05\right)$, suggesting our sample is balanced

153 between sexes and ages.

Sample treatment and measurements

156 Post-mortem examinations were performed by trained veterinarians. Dutch seals were examined at

157 Sealcentre Pieterburen and German seals were necropsied at the Institute for Terrestrial and Aquatic

158 Wildlife Research (ITAW), Büsum, Germany. Necropsies were performed on either cooled or defrosted

159 carcasses. Body weight, body length and axillary girth were all measured prior to the start of the

160 necropsy. Body length was measured from the tip of the nose to the end of the tail in a non-curvilinear

161 fashion, while the animal was in supine position, and axillary girth was measured as the body

162 circumference directly caudal to the front flippers. The vocal apparatus including the upper vocal tract,

163 the larynx, and part of the trachea was then removed and immediately frozen at $-20^{\circ} \mathrm{C}$. All samples were

164 in a similar condition (i.e., none presented signs of decomposition), comparable to pinniped vocal tracts in

165 Schneider (1962) and Ravignani and colleagues (2017).

167 Prior to measurement, samples were thawed in a refrigerator at $8^{\circ} \mathrm{C}$ and each larynx was cut medially to

168 produce two hemi-vocal tracts. The measurements taken on these hemi-vocal tracts include vocal tract

169 length (VTL), vocal fold length (VFL), vocal fold thickness (VFT), and tracheal measurements in the

170 form of subglottic-tracheal dorsoventral distances (STDVs) (called subglottic-tracheal anterior-posterior

171 distance, STAP, in Roers, Mürbe, \& Sundberg, 2009) using a calliper to an accuracy of $\pm 0.01 \mathrm{~mm}$ (see

172 Figure 2). Although the vocal tract can be divided into lower (below larynx) and upper (above larynx)

173 sections, formants (the resonant frequencies which often encode information about body size) are only

174 determined by the upper vocal tract (Lester \& LaGasse, 2008). VTL will henceforth refer to the length of

175 the upper vocal tract. VTL was measured as the linear distance from the caudal end of the epiglottis to the 
176 rostral end of the tongue muscle while the tongue was kept straight. VFL was measured as the distance

177 from the ventral attachment of the vocal fold on the thyroid cartilage to the dorsal attachment of the vocal

178 fold on the arytenoid cartilage. VFT was measured as the distance between the anterior and posterior

179 sides of the vocal folds. The first STDV was measured as the distance between the cricothyroid ligament

180 and the caudal end of the arytenoid. The second STDV was measured as the diameter of the first tracheal

181 ring. All measurements were performed independently by two researchers. For both researchers, VTL,

182 VFL, and VFT were measured twice for each hemi-vocal tract, and STDVs were taken once for each

183 hemi-larynx because the start and end measuring points were composed of cartilage (as opposed to soft

184 tissue) and hence, we assumed that the inter-rater reliability for STDVs would be higher than for other

185 measurements. 


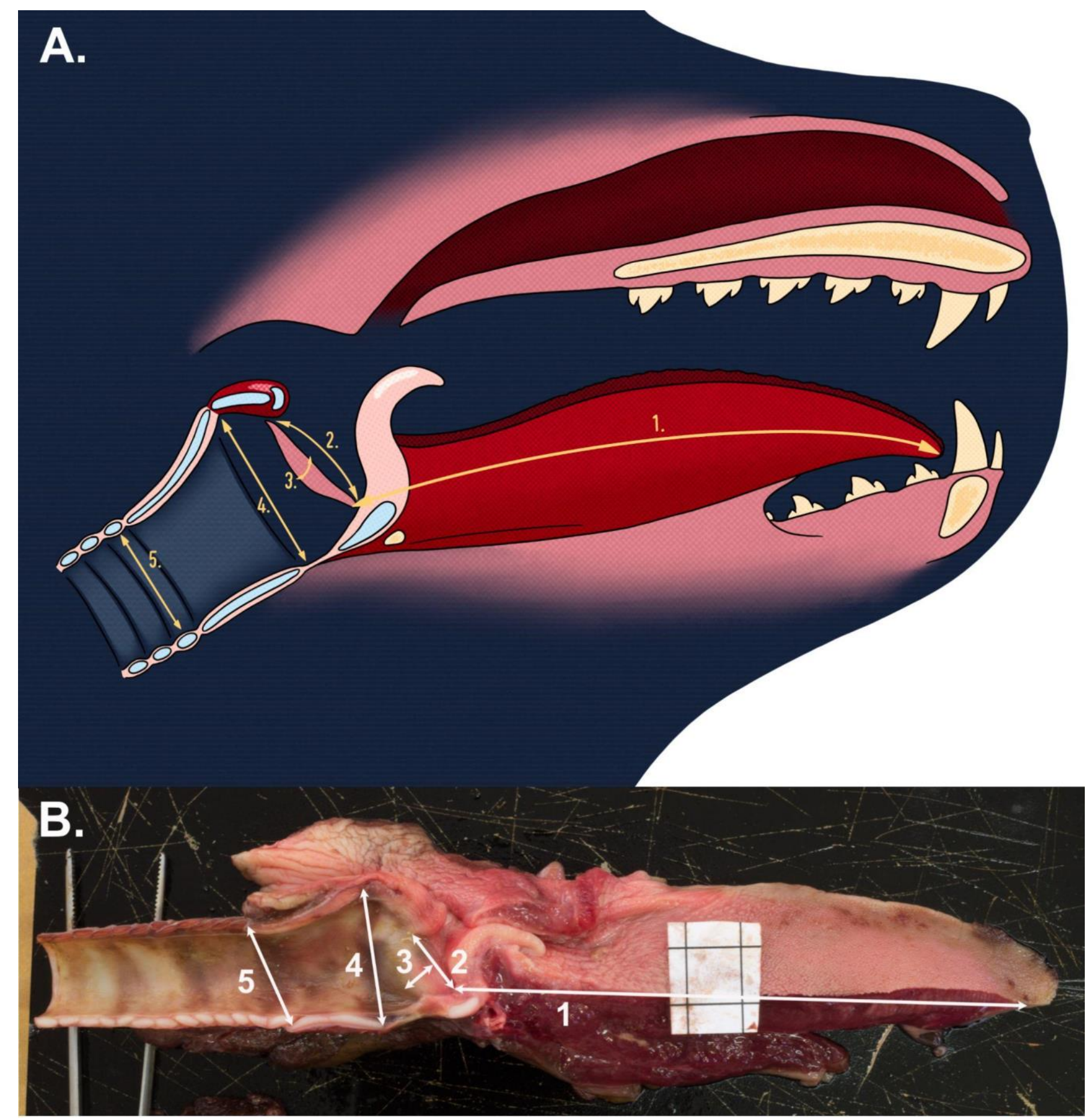

Figure 2. Images depicting the measurements taken using (A) a digital rendering of the vocal tract and (B) one hemi-larynx of a harbour seal pup. The vocal tract measurements taken include (1) vocal tract length (VTL), (2) vocal fold length (VFL), (3) vocal fold thickness (VFT), (4) subglottic-tracheal dorsoventral distance 1 (STDV1), and (5) subglottic-tracheal dorsoventral distance 2 (STDV2). In panel $\mathrm{B}$, the black square outlined on the white paper serves as reference and is exactly $1 \mathrm{~cm}^{2}$. 
Statistical analysis

195 Statistical analyses were performed in RStudio version 1.1.463 (R version 4.0.4). First, for both raters, the

196 medians for VTL, VFL and VFT were computed from all values reported for every right and left hemi-

197 larynx. Second, using the medians from the first step, the median values for all measurements including

198 STDV1 and STDV2 were computed for each larynx. This provided, for each larynx and rater, five

199 measurements: VTL, VFL, VFT, STDV1 and STDV2. The inter-rater reliability for VTL, VFL, VFT,

200 STDV1 and STDV2 was evaluated using Pearson's correlations. Finally, the overall median values

201 between raters were computed for all measurements. Using these new values, Spearman's correlations

202 between body size and vocal anatomy measurements were then calculated (see Table 1). For each

203 measurement, normality was assessed using the Shapiro-Wilk test and homogeneity of variance was

204 assessed using an F-test. If both assumptions were met, a two-tailed independent samples t-test was

205 computed to check for age and sex differences. When variables were not normally distributed, but

206 samples had equal variance, a Mann Whitney U-test was performed to assess group differences instead.

207

208

Table 1

209

Pairwise Spearman correlations

210

\section{1}

Variable

$$
\begin{gathered}
\begin{array}{c}
\text { Length } \\
(\mathrm{cm})
\end{array} \\
0.70
\end{gathered}
$$

\begin{tabular}{l|l} 
Weight $(\mathrm{kg})$ & 0.70
\end{tabular}

\begin{tabular}{l|ll} 
Girth $(\mathrm{cm})$ & $0.53 \quad 0.86$
\end{tabular}

\begin{tabular}{l|lll}
$\operatorname{VTL}(\mathrm{mm})$ & 0.62 & 0.69 & 0.63
\end{tabular}

\begin{tabular}{c|cccccc} 
VFL $(\mathrm{mm})$ & 0.73 & 0.79 & 0.65 & 0.72 & & \\
VFT $(\mathrm{mm})$ & 0.44 & 0.67 & 0.68 & 0.52 & 0.60 & \\
STDV1 $(\mathrm{mm})$ & 0.63 & 0.78 & 0.65 & 0.70 & 0.82 & 0.69 \\
STDV2 $(\mathrm{mm})$ & 0.58 & 0.72 & 0.62 & 0.67 & 0.76 & 0.60
\end{tabular}

$\begin{array}{ccccc}\text { Girth } & \text { VTL } & \text { VFL } & \text { VFT } & \text { STDV1 } \\ (\mathrm{cm}) & (\mathrm{mm}) & (\mathrm{mm}) & (\mathrm{mm}) & (\mathrm{mm})\end{array}$

212 Note. All correlations were significant at $p<0.05$ after correcting for multiple comparisons using the 213 Holm-Bonferroni method. 
215 Predictive modelling was done using generalised linear models (GLMs) with the stats package (R Core

216 Team, 2013). A series of models were produced for all anatomical measurements with high inter-rater

217 reliability $(r>0.70)$. For every response variable, the full model included the fixed effects length, weight,

218 girth, sex, age and the interaction effects of sex with all body size predictors, age with all body size

219 predictors and the interaction of age and sex. The reduced model was then obtained through stepwise

220 regression based on Akaike Information Criterion (AIC) values. An analysis of variance (ANOVA) test

221 was performed to ensure that the reduced model was not performing significantly worse than the full one.

222 Variance inflation factors (VIF) scores were calculated for all predictors included in the reduced models

223 using the car package (Fox \& Weisberg, 2019). Multicollinearity was considered problematic for

224 subsequent model selection if VIF scores were greater than 5 (Akinwande, Dikko, \& Samson, 2015). For

225 all selected models, deviance explained was calculated from the model output (1 - residual deviance / null

226 deviance) and expressed as a percentage. Plots displaying the predicted effects of every predictor retained

227 in the final models were produced to assess their relationship with the response variable. Diagnostic

228 residual plots were used to verify the model assumptions. Independence of residuals was tested using a

229 Durbin Watson test (Fox \& Weisberg, 2019). Normality of residuals was assessed visually by plotting

230 model fit against the observed data. Homoscedasticity (i.e., constant variance) of residuals was also

231 assessed visually using quantile-quantile plots. Finally, influential data points were assessed by

232 calculating Cook's distance. 


\section{$\underline{\text { Results }}$}

Inter-rater reliability for VTL, VFL, VFT, and both STDVs was evaluated using Pearson correlations. VTL $(r=0.94)$, VFL $(r=0.88)$, STDV1 $(r=0.97)$ and STDV2 $(r=0.93)$ showed high inter-rater reliability. VFT $(r=0.59)$ showed lower inter-rater reliability and was consequently excluded from

238 further analysis. All correlations were significant at $p<0.001$.

All Spearman correlations between body size and vocal anatomy measurements showed positive

241 relationships and significance at the 0.05 level (see Table 1). There were high correlations between

242 weight and length $\left(r_{s}=0.70\right)$, and between weight and girth $\left(r_{s}=0.86\right)$. Other notable correlations

243 included those between VTL and VFL $\left(r_{s}=0.72\right)$, VTL and STDV1 $\left(r_{s}=0.70\right)$, VFL and STDV1 $\left(r_{s}=\right.$

244 0.82), VFL and STDV2 $\left(r_{s}=0.76\right)$. Spearman correlations for pups and weaners can be found in Tables

$245 \quad 2-3$ of the Supplement.

All anatomical measurements were non-normally distributed but showed equal variances across age and sex groups. A Mann Whitney U-test was used to test for group differences in both variables as only the assumption for homogeneity of variance was satisfied. All anatomical measurements were significantly larger in weaners than in pups ( $p<0.001$; see Table 2 and Figure 3). No significant sex differences were found when considering pups and weaners together $(p>0.05)$. When considering pups alone, both the normality and homoscedasticity assumptions were met. A two-tailed independent samples t-test found significant sex differences for vocal tract length $(t=-3.416, p<0.05$; see Figure 4A). Male pups (86.03 $\mathrm{mm} \pm 2.92)$ had a larger mean VTL than females $(79.80 \mathrm{~mm} \pm 3.68)$. When considering weaners alone, variables showed non-normal distribution, but equal variances. A series of Mann Whitney U-tests found that only the first subglottic-tracheal dorsoventral distance was significantly different across sexes $(U=$ 218, $p<0.05$; see Figure 4B). Weaned males $(25.12 \mathrm{~mm} \pm 1.50)$ had a wider mean STDV1 compared to weaned females $(24.22 \mathrm{~mm} \pm 1.24)$. 
bioRxiv preprint doi: https://doi org/10.1101/2021.1029.466455; this version posted November 5, 2021. The copyright holder for this preprint (which was not certified by peer review) is the author/funder, who has granted bioRxiv a license to display the preprint in perpetuity. It is made available under aCC-BY-NC 4.0 International license.

\begin{tabular}{|c|c|c|c|c|c|c|}
\hline & \multicolumn{2}{|c|}{ All } & \multicolumn{2}{|c|}{ Pups } & \multicolumn{2}{|c|}{ Weaners } \\
\hline Variable & Mean & SD & Mean & $\mathrm{SD}$ & Mean & SD \\
\hline Length $(\mathrm{cm})$ & 88.07 & 8.03 & 79.86 & 4.79 & 90.19 & 7.32 \\
\hline Weight (kg) & 14.53 & 3.92 & 9.81 & 1.46 & 15.75 & 3.39 \\
\hline Girth (cm) & 57.55 & 9.62 & 46.54 & 5.66 & 60.41 & 8.30 \\
\hline VTL (mm) & 91.43 & 6.77 & 83.36 & 4.48 & 93.53 & 5.60 \\
\hline VFL (mm) & 10.92 & 1.16 & 9.26 & 0.90 & 11.35 & 0.77 \\
\hline VFT (mm) & 5.15 & 0.61 & 4.50 & 0.43 & 5.35 & 0.51 \\
\hline STDV1 (mm) & 23.97 & 1.95 & 21.35 & 1.37 & 24.65 & 1.43 \\
\hline STDV2 (mm) & 17.43 & 1.82 & 15.17 & 1.04 & 18.02 & 1.49 \\
\hline
\end{tabular}


(A) VTL

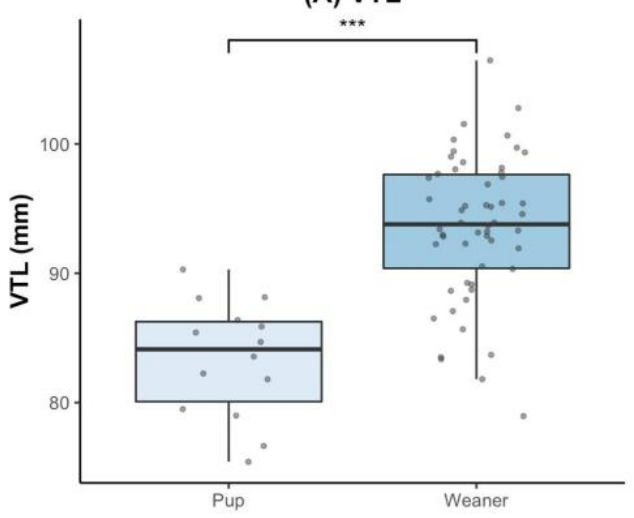

(C) STDV1

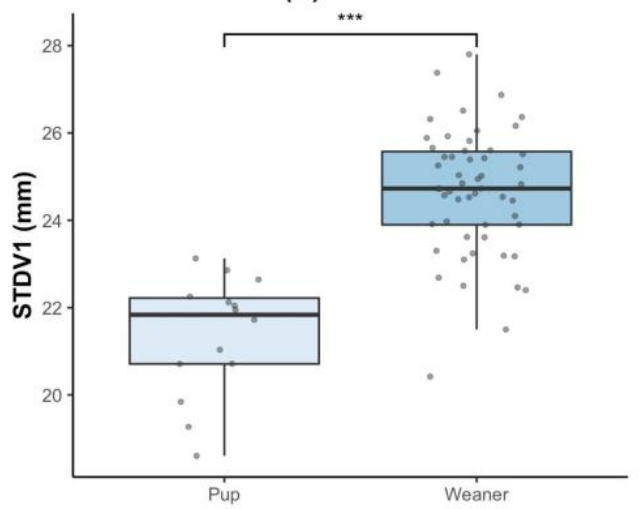

(B) VFL

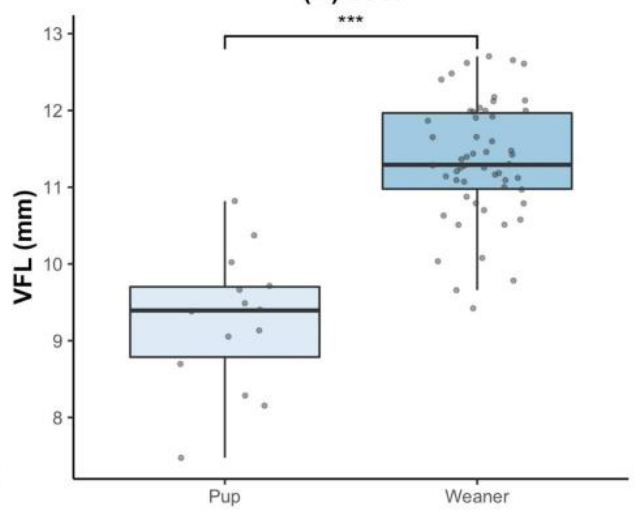

(D) STDV2

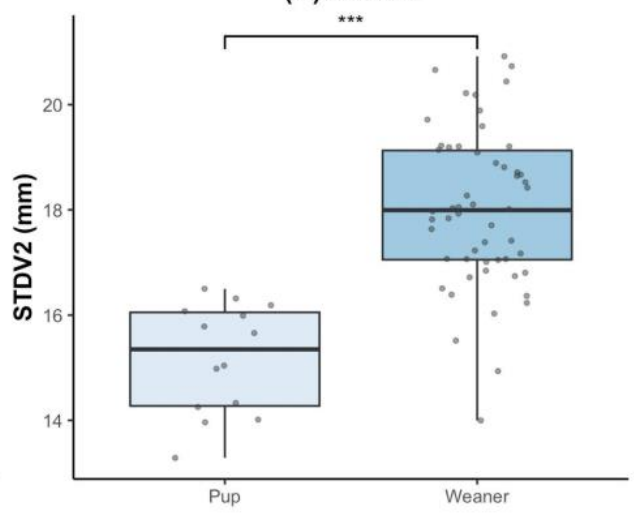

Figure 3. Boxplots illustrating the significant age differences between pups and weaners for (A) VTL,

(A) Pup VTL

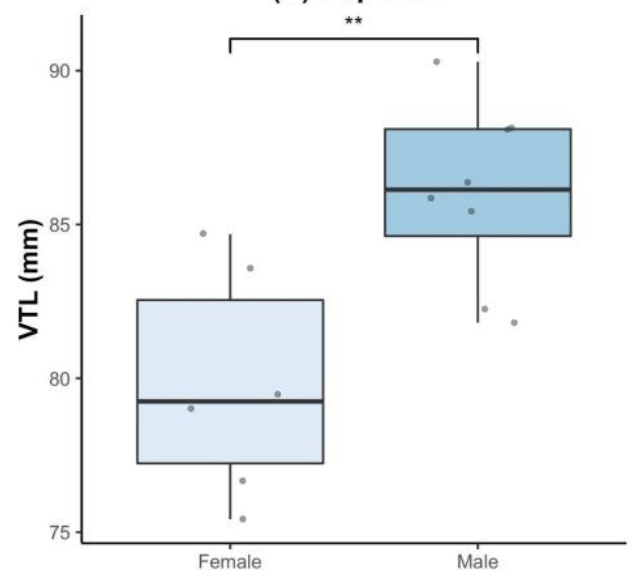

(B) Weaner STDV1

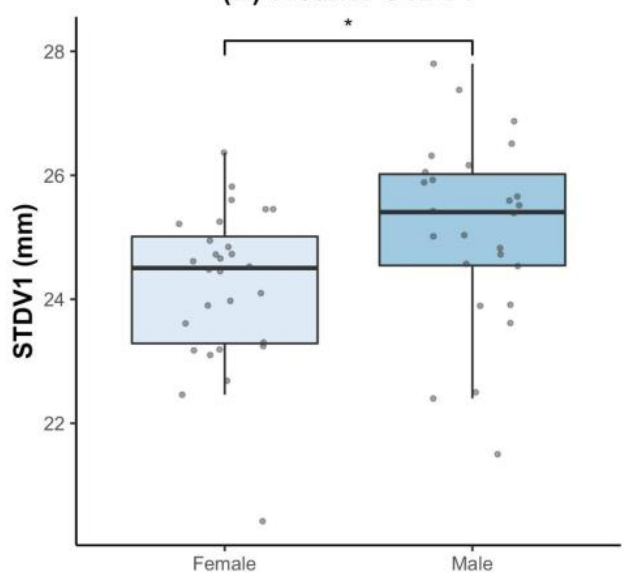

Figure 4. Boxplots illustrating the significant sex differences for (A) VTL in pups and (B) STDV1 in weaners. The level of significance is denoted by asterisks, where $*=0.05$ and $* *=0.01$. 
276 A reduced GLM, obtained by stepwise regression based on AIC values, was produced for every vocal

277 tract measurement with high inter-rater reliability, including VTL, VFL, STDV1 and STDV2. All VIF

278 scores were lower than 5 suggesting that multicollinearity was not problematic in the selected models. All

279 model assumptions were satisfied. Moreover, ANOVA testing indicated that the reduced models did not

280 perform significantly worse than the full models $(p>0.90)$. GLM results showed that most vocal tract

281 dimensions were best explained by length, weight, age, and sex (see Table 3). Girth was not retained as a

282 predictor term in any of the selected models. For each model, the predictor estimates with their

283 confidence intervals can be found in Tables 4-7 of the Supplement and plots of the predicted effects can

284 be found in Figures 1-5 of the same document. Significant interaction effects are shown in Figure 5.

286 Table 3

287 Selected models for each vocal tract structure

\begin{tabular}{ccc}
\hline Measurement & Selected model & Deviance explained (\%) \\
\hline VTL & $\underline{\mathrm{L}}+\underline{\mathrm{W}}+\underline{\mathrm{A}}+\underline{\mathrm{S}}+\underline{\mathrm{L}} * \underline{\mathrm{S}}$ & 59.30 \\
VFL & $\underline{\mathrm{L}}+\mathrm{W}+\mathrm{A}+\underline{\mathrm{S}}+\mathrm{A} * \mathrm{~W}+\underline{\mathrm{A} * \mathrm{~S}}$ & 74.89 \\
STDV1 & $\underline{\mathrm{L}}+\underline{\mathrm{W}}+\underline{\mathrm{A}}+\underline{\mathrm{S}}$ & 69.99 \\
STDV2 & $\mathrm{L}+\underline{\mathrm{W}}+\underline{\mathrm{A}}+\mathrm{S}$ & 58.38 \\
\hline
\end{tabular}

Note. Models included the predictors length (L), weight (W), age class (A) and sex (S). Predictor terms

289 joined by an asterisk denote an interaction effect. Significant predictor terms are shown as underlined. 
Predicted values of VTL

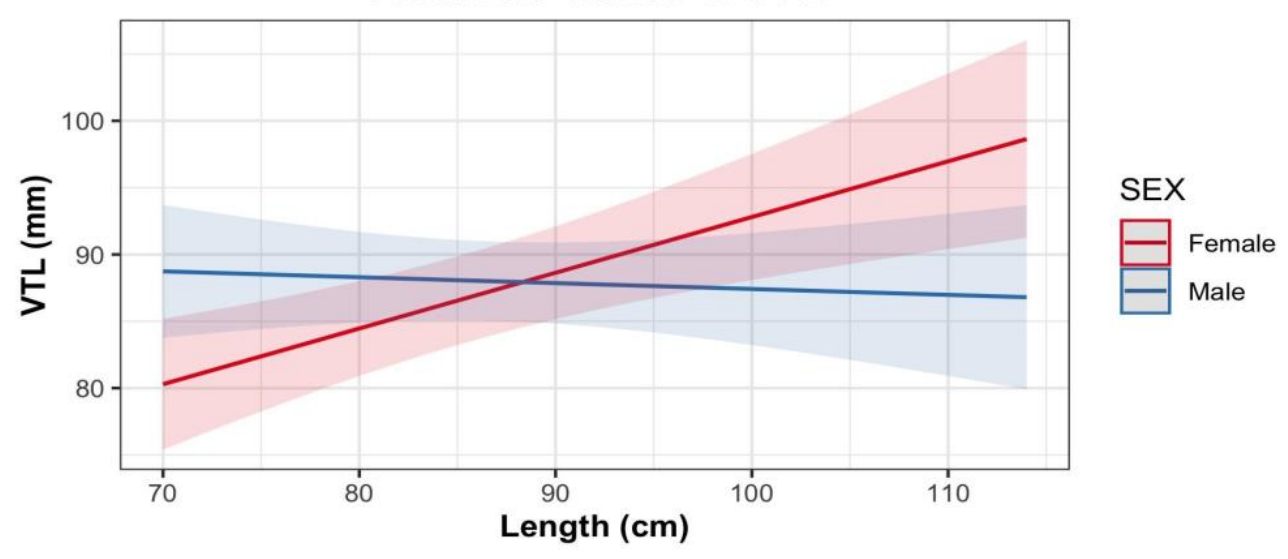

Predicted values of VFL

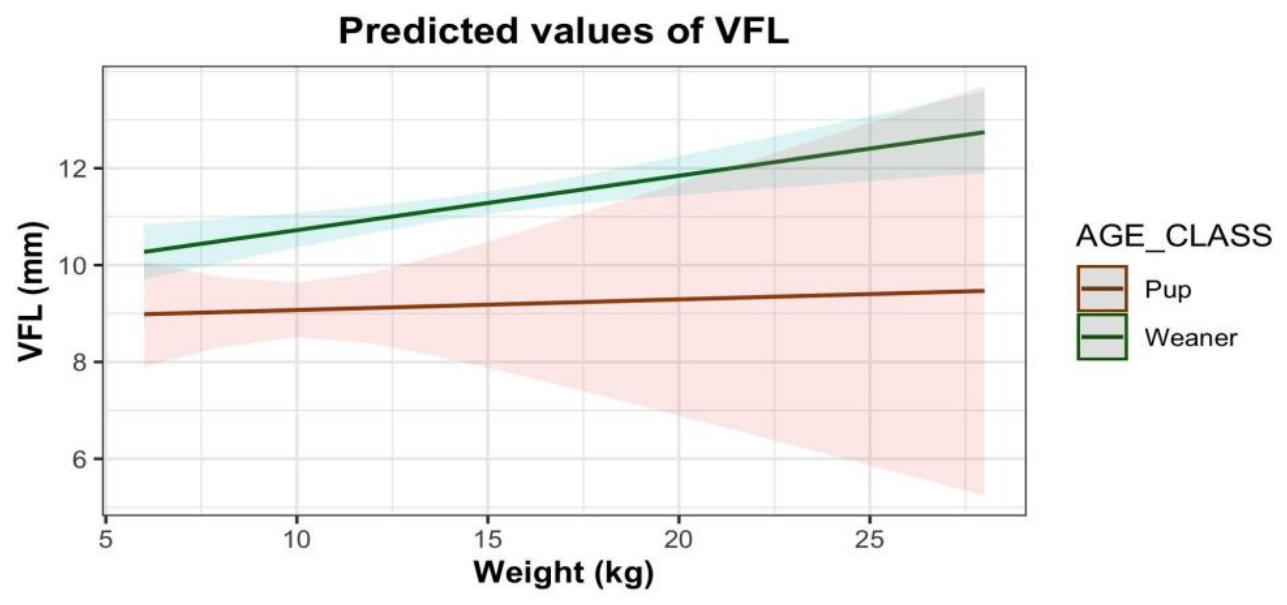

Figure 5. Predicted effects of the body length and sex interaction for VTL including both age classes (top), and the weight and age interaction for VFL including both sexes (bottom). The shading around each line of best fit indicates the $95 \%$ confidence interval.

$\underline{\text { Discussion }}$

299 This study reports on the allometric relationships between body size and vocal tract dimensions in

300 harbour seals. It shows that body length accurately predicts VTL, VFL, and STDV1, and body weight

301 predicts VTL and both tracheal measurements (STDVs). We also find age and sex to be important

302 predictors for the size of vocal tract structures. This is evidenced by significant differences in measurements between age classes and significant sexual differences within age classes.

305 Previous work showed that upper vocal tract (i.e., filter) dimensions in mammals are predicted by body 306 size measurements (Fitch, 1997; Fitch \& Giedd, 1999; Fitch, 2000; Plotsky, Rendall, Riede, \& Chase, 307 2013; Garcia et al., 2016, Ravignani et al., 2017) and our results provide additional evidence to support 
such allometry. Although most studies have used body length as a proxy for body size, we find that body weight can also be used to predict VTL in harbour seals. In the first years of life, harbour seals show a linear growth rate for both length (Haukkson, 2006) and weight (Markussen, Bjørge, \& Øritsland, 1989), suggesting that VTL may develop in a similar fashion during this period. Acoustic proxies for the filter could thus provide a good estimation of a harbour seal's size. In mammals, formant frequencies and formant spacing can be predicted from VTL and vice versa (see Reby \& McComb, 2003). Other acoustic proxies include energy quartiles, the frequency of amplitude peaks, and the ratios between these amplitudes (Sauvé et al., 2015). These parameters also encode individual signatures, suggesting that acoustic individuality may partially be an allometric by-product (Ravignani et al., 2017). Harbour seals have the vocal tract predispositions to produce vocalisations that accurately reflect body size whilst also sharing individual-specific information, suggesting that learning does not need to be invoked to explain individuality.

Across mammals, source-related features such as F0 can sometimes predict body size despite showing weaker allometric scaling than filter-related features (Reby \& McComb, 2003; Charlton et al., 2011; Pfefferle et al., 2007; Charlton \& Reby, 2016); it was unclear whether this holds for harbour seals (Ravignani et al., 2017; Bowling et al., 2017). Our findings indicate that vocal fold length, which may be used to approximate F0, can be predicted by body size in harbour seals. Moreover, Sauvé and colleagues (2015) reported a decrease in F0 with an increase in body length of harbour seal pups. Taken together, this suggests that a harbour seal's F0 can be predicted from vocal anatomy. Previous evidence against allometric scaling for VFL could be explained by low statistical power or lack of testing for age effects on vocal tract measurements (Ravignani et al., 2017). It is indeed notable that age is included in both interactions which were retained in the selected VFL model. Our results, including both pups and weaners, show that allometric scaling between body size and VFL only emerges after weaning, suggesting that VFL may not be constrained in harbour seal pups (see bottom panel of Figure 5). This begs the following question: how would escaping acoustic allometry for source-related features be beneficial for pups? Broadcasting honest body size information may be detrimental for harbour seal pups as they are significantly more likely to be displaced by larger conspecifics during agonistic interactions (Neumann, 1999). However, pups may be able to benefit from lowering the F0 (Borda et al., 2021) of their calls to create an impression of size exaggeration. On the other hand, pups may also benefit from

338 increasing the F0 of their calls to create an impression of distress to the mother (Briefer, 2012). Future 339 playback studies could contrast these hypotheses. 
Several phocid species use the trachea for sound production (Bryden \& Felts, 1974), but this could be a by-product of adaptive modifications to the respiratory tract required for diving (Kooyman \& Andersen, 1969; Tyack \& Miller, 2002). Our results support the correlation between tracheal diameter and body length found by Ravignani and colleagues (2017), but also provide evidence that tracheal dimensions can be predicted by body weight. Previous literature found that the trachea may potentially convey body size information if its size influences acoustic call features (Ravignani et al., 2017). In humans, a wider tracheal diameter partially predicts turbulence (i.e., unsteady air movements) for large airflows (Van den Berg, Zantema, \& Doornenbal, 1957). Applying the same logic to other mammals, larger seals would have wider tracheal dimensions which, in turn, would make vocalisations noisier. This could explain, for instance, why the signal-to-noise ratio decreases as harbour seals get older (de Reus, 2017; de Reus, Jadoul, \& Ravignani, in prep.). Future work on sound production in this species could test this prediction using sound-anatomy correlations and excised larynx set-ups. Moreover, playback experiments could test whether adding noise to vocalisations alters interactive behaviour to determine if signal-to-noise ratio may encode body size information. Understanding whether the trachea is actively involved in sound production will thus require further research.

As expected, all anatomical measurements are larger for weaners than they are for pups. In Ravignani and colleagues (2017), animals up to 108 days old were classified as pups. However, in the wild, the lactation period for harbour seals ranges from 23 to 42 days, after which the pups are weaned (Renouf, 2012). Hence, for the sake of simplicity, we consider animals up to one month old as pups and animals older than one month as weaners. Thanks to this categorical classification, we were able to identify how allometric trends develop over the harbour seal's early life. Future research including larynges from subadults and adults will further extend our knowledge of how vocal allometry develops in harbour seals.

There were no sexual differences when considering the sample size as a whole, but significant sexual differences existed within age classes. These differences could be attributed to differing levels of steroid hormones acting on the laryngeal structures in males and females (Aufdemorte, Sheridan, \& Holt, 1983; Sauvé et al., 2015). In some mammals, sex hormones affect the structural development of the larynx and the viscoelastic properties of the vocal fold tissue (Fitch \& Giedd, 1999; Beckford, Schaid, Rood, \& Schanbacher, 1985). At puberty, the male larynx descends in the vocal tract causing an elongation of the length of the upper vocal tract, allowing males to convey an exaggerated impression of size (Fitch \& Giedd, 1999; Fitch \& Reby, 2001). In harbour seal pups, males have larger VTLs than females, suggesting that laryngeal descent in males possibly occurs early in life. Once weaned, however, females show a clear increase in VTL whereas it remains relatively constant in males (see top panel of Figure 5), 
suggesting that VTL differences across sexes may become less pronounced over time. In mammalian males, sex hormone action also causes a rapid increase in cartilage size leading to an enlarged larynx and an increase in the vibrating portion of the vocal folds (Fitch \& Hauser, 2003). This could explain why, in weaners, STDV1 is larger in males than in females. Nevertheless, these findings are somewhat surprising as young harbour seals normally show little sexual dimorphism (Le Boeuf, 1991). In particular, there is a lack of evidence for sexual differences regarding birth mass and growth rates among harbour seal pups (Bowen, Oftedal, Boness, \& Iverson, 1994). In our sample, there are no significant body size differences between sexes $(p>0.05)$, but male pups are slightly larger than female pups in both body length $(\mathrm{M}=$ $81.63 \mathrm{~cm} \pm 4.44, \mathrm{~F}=77.50 \mathrm{~cm} \pm 4.51)$ and weight $(\mathrm{M}=9.82 \mathrm{~kg} \pm 1.49, \mathrm{~F}=9.78 \mathrm{~kg} \pm 1.55)$. It is important to note that the sampled animals were sick and/or in poor condition; hence weight values are not representative of healthy individuals and should be interpreted with caution. In short, based on these observed differences in vocal anatomy across sexes, formants are expected to differ in pups and signal-tonoise ratio is expected to differ in weaners. The anatomical structures that determine these acoustic features both show strong allometric scaling, hence these parameters may provide distinct body size cues across age classes, potentially facilitating the discrimination of male and female conspecific calls. Sexual selection could thus play a role in driving size differences in VTL and STDV1, but it is yet unknown if these differences are maintained throughout developmental life stages. Future research should aim to investigate the elastic properties of harbour seal laryngeal tissues and to understand how sex hormones affect these properties. Hormone levels can be measured by taking blood samples from healthy male and female seals at different developmental stages, and results can be combined with magnetic resonance imaging (MRI) mapping of laryngeal tissue elasticity.

The high inter-rater reliability observed for VTL, VFL and both STDVs demonstrates that these quantities can be measured and replicated easily, making them reliable landmarks for vocal tract measurements. However, tissue properties such as the viscoelasticity of certain vocal tract structures, like the vocal folds, are significant obstacles to getting accurate measurements. Indeed, raters struggled to produce precise data for VFT. Future research in the field of pinniped vocal anatomy would benefit from improved measuring techniques using 2D pictures, radiography, MRI and computed tomography (CT) scans as this would enable more accurate measurements for structures that are difficult to handle. Finally, future similar studies should include measurements of another vocal tract structure: the corniculate cartilage.

406 help close the trachea together with the epiglottis (Adams et al., 2020). These cartilages are located close 407 to the vocal folds and are possibly innervated by the same nerves and controlled by the same muscles. It 408 may be possible that these cartilages play a role in sound production by, for example, lowering the F0 by 
adding weight to the vocal folds. Taken together, these suggestions will provide a more precise and detailed picture of the harbour seal's vocal anatomy.

412 Observed species-specific vocalisations are determined by both the species' vocal anatomy and their 413 capacity for vocal learning (Garcia \& Ravignani 2020; Ravignani \& Garcia 2021). The vocal anatomy 414 generates vocal predispositions by imposing biomechanical constraints, whereas neural processes 415 determine the degree of control species have over their vocal organs (Garcia \& Manser, 2020).

416 Particularly, vocal learners, like the harbour seal, are capable of actively modulating sounds, suggesting 417 that they are less constrained by anatomy and have a refined capacity for vocal motor control.

418 Unfortunately, the relative contribution of both sound production mechanisms is unclear. Here, we test a 419 hypothesis trying to segregate anatomical vs. learning mechanisms (Garcia \& Ravignani, 2020; Ravignani $420 \&$ Garcia 2021). As shown here, by testing for allometric relationships between body size and vocal tract structures, one can start to disentangle the respective contributions of vocal anatomy and vocal motor control in shaping acoustic signals. We find that harbour seals are mechanistically constrained by their vocal anatomy, and their large vocal flexibility (Ralls et al., 1985; Borda et al., 2021), which may result in the production of dishonest signals, thus points towards extensive volitional control over their vocalisations. In brief, we provide support for the morphology vs. learning hypothesis, showing however that this relation may be mediated by ontogeny.

In sum, we provide evidence of allometry between body size and vocal tract measurements in harbour seals. Body length is a strong predictor for VTL, VFL, and STDV1, and body weight is a strong predictor for VTL and both tracheal measurements (STDVs). Age and sex are also important in predicting the dimensions of these anatomical structures. Taken together, the combined findings demonstrate that harbour seal vocal tracts do indeed scale with body size, although allometry between VTL and body size may only emerge after weaning. Inferences, based on their vocal tract or body size, can now be made

434 about the vocal predispositions of harbour seals (e.g., F0, formants, signal-to-noise ratio). Comparing 435 these predictions to data obtained from observed natural vocalisations will shed light on the range of 436 vocal flexibility resulting from their extensive vocal motor control. Moreover, connecting harbour seals'

437 vocal anatomy measurements to the vocalisations they produce while alive is a critical next step to 438 directly relate acoustic features to sound production structures. Integrating such results with investigations 439 of call function will eventually inform on which vocal structures are responsible for generating the 440 individual- and species-specific information encoded in harbour seals' vocalisations. 


\section{$441 \quad$ List of symbols and abbreviations}

442 F0 - Fundamental frequency

$443 \mathrm{C}-$ Celsius

444 VTL - Vocal Tract Length

445 VFL - Vocal Fold Length

446 VFT - Vocal Fold Thickness

447 STDV - Subglottic-Tracheal Dorsoventral distance

448 STAP - Subglottic-Tracheal Anterior-Posterior distance

449 GLM - Generalised Linear Model

450 AIC - Akaike Information Criterion

451 ANOVA - ANalysis Of VAriance

452 VIF - Variance Inflation Factor

$453 \quad \mathrm{M}-$ Male

$454 \quad \mathrm{~F}-$ Female

$455 \mathrm{~kg}-$ kilogram

$456 \mathrm{~cm}$ - centimetre

457 MRI - Magnetic Resonance Imaging

458 CT - Computed Tomography 


\section{Acknowledgments}

We are grateful to Letty Stupers, Rebecca Andreini, Maria Jose Robles for helping in gathering and preparing samples for data collection. We thank Aline Joustra for her illustrations of seal vocal tracts. We also greatly appreciate the extensive comments provided by Taylor Hersh and Laura Verga. We would also like to thank all members and volunteers of Sealcentre Pieterburen for their continued support in this research.

\section{Competing interests}

467 The authors declare no competing interests.

\section{Author contributions}

$\mathrm{KdR}, \mathrm{SG}, \mathrm{MG}, \mathrm{ASC}, \mathrm{ARG}$, and AR conceived the research and designed the experiment. KdR, AR and SG collected the data. KdR, SG, ASC, ARG, and AR collected the data. KdR, DC, and AL performed the statistical analysis. All authors interpreted the results, drafted the article, and helped to critically revise it.

\section{Funding}

This work was supported by a Max Planck Research Group (MPRG) and a FWO Pegasus Marie Curie fellowship $12 \mathrm{~N} 5517 \mathrm{~N}$ awarded to AR. KdR was supported by the FWO project 'Interactive vocal rhythms' G034720N awarded to Bart de Boer. The German Ministry of Energy, Agriculture, the Environment, Nature and Digitalization (MELUND) funded the marine mammal stranding scheme and the necropsies at the Sealcentre Pieterburen. MG was supported by a research grant from the Ethologische

\section{$\underline{\text { Reference list }}$}

Adams, A., Vogl, W., Dawson, C., Raverty, S., Haulena, M., \& Skoretz, S. A. (2020). Laryngeal and soft palate valving in the harbour seal (Phoca vitulina). Journal of Experimental Biology, 223(20). laryngeal tissues of the baboon (Papio cynocephalus). The Laryngoscope, 93(12), 1607-1611. https://doi.org/10.1288/00005537-198312000-00013 
Bjørge, A., Desportes, G., Waring, G. T., \& Rosing-Asvid, A. (2010). Introduction: the harbour seal (Phoca vitulina)-a global perspective. NAMMCO Scientific Publications, 8, 7-11.

Borda, L. T., Jadoul, Y., Rasilo, H., Casals, A. S., \& Ravignani, A. (2021). Vocal plasticity in harbour seal pups. Philosophical Transactions of the Royal Society B: Biological Sciences. 376, 20200456. https://doi.org/10.1098/rstb.2020.0456

Bowen, W. D. (1991). Behavioural ecology of pinniped neonates. In The Behaviour of Pinnipeds (pp. 66-127). Springer Netherlands. https://doi.org/10.1007/978-94-011-3100-1_3

Bowen, W., Oftedal, O., Boness, D., \& Iverson, S. (1994). The effect of maternal age and other factors on birth mass in the harbour seal. Canadian Journal of Zoology, 72, 8-14.

Bowling, D. L., Garcia, M., Dunn, J. C., Ruprecht, R., Stewart, A., Frommolt, K. H., \& Fitch, W. T. (2017). Body size and vocalization in primates and carnivores. Scientific reports, 7(1), 1-11.

Briefer, E. F. (2012). Vocal expression of emotions in mammals: mechanisms of production and evidence. Journal of Zoology, 288(1), 1-20.

Bryden, M. M., \& Felts, W. J. (1974). Quantitative anatomical observations on the skeletal and muscular systems of

Charlton, B., Ellis, W., McKinnon, A., Cowin, G., Brumm, J., Nilsson, K., \& Fitch, W. (2011). Cues to body size in the formant spacing of male koala (Phascolarctos cinereus) bellows: honesty in an exaggerated trait. Journal of Experimental Biology, 214(20), 3414-3422. https://doi.org/10.1242/jeb.061358

Charlton, B. D., \& Reby, D. (2016). The evolution of acoustic size exaggeration in terrestrial mammals. Nature Communications, 7(1), 1-8. https://doi.org/10.1038/ncomms12739

Charlton, B., Zhihe, Z., \& Snyder, R. (2009). The information content of giant panda, Ailuropoda melanoleuca, bleats: acoustic cues to sex, age and size. Animal Behaviour, 78(4), 893-898.

Fant, G. (1970). Acoustic theory of speech production (2nd ed.). The Hague: Mouton.

Fitch, W. T. (1997). Vocal tract length and formant frequency dispersion correlate with body size in rhesus macaques. The Journal of the Acoustical Society of America, 102(2), 1213-1222. https://doi.org/10.1121/1.421048

Fitch, W.T. (2000). The evolution of speech: a comparative review. Trends in Cognitive Sciences, 4(7), 258-267.

Fitch, W. T., \& Giedd, J. (1999). Morphology and development of the human vocal tract: A study using magnetic resonance imaging. The Journal of the Acoustical Society of America, 106(3), 1511-1522. https://doi.org/10.1121/1.427148

Fitch, W. T., \& Hauser, M. D. (1995). Vocal production in nonhuman primates: Acoustics, physiology, and functional constraints on "honest" advertisement. American Journal of Primatology, 37(3), 191-219. https://doi.org/10.1002/ajp.1350370303

Fitch, W. T., \& Hauser, M. D. (2003). Unpacking "Honesty": Vertebrate Vocal Production and the Evolution of Acoustic Signals. In Acoustic Communication (pp. 65-137). Springer-Verlag. https://doi.org/10.1007/0387-22762-8_3

Fitch, W.T., \& Reby, D. (2001). The descended larynx is not uniquely human. Proceedings of the Royal Society of London. Series B: Biological Sciences, 268(1477), 1669-1675. https://doi.org/10.1098/rspb.2001.1704 
Fox, J., \& Weisberg, S. (2019). An R Companion to Applied Regression, Third edition. Sage, Thousand Oaks CA. https://socialsciences.mcmaster.ca/jfox/Books/Companion/.

Garcia, M., Herbst, C. T., Bowling, D. L., Dunn, J. C., \& Fitch, W. T. (2017). Acoustic allometry revisited: morphological determinants of fundamental frequency in primate vocal production. Scientific reports, 7(1), $1-11$.

Garcia, M., \& Manser, M. (2020). Bound for Specific Sounds: Vocal Predisposition in Animal Communication. Trends in Cognitive Sciences, 24(9), 690-693.

Garcia, M., \& Ravignani, A. (2020). Acoustic allometry and vocal learning in mammals. Biology Letters, 16(7), 20200081.

Garcia, M., Wondrak, M., Huber, L., \& Fitch, W. T. (2016). Honest signaling in domestic piglets (Sus scrofa domesticus): vocal allometry and the information content of grunt calls. The Journal of Experimental Biology, 219, 1913-1921. https://doi.org/10.1242/jeb.138255

Hanggi, E. B., \& Schusterman, R. J. (1994). Underwater acoustic displays and individual variation in male harbour seals, Phoca vitulina. Animal Behaviour, 48(6), 1275-1283. https://doi.org/10.1006/anbe.1994.1363

Hauksson, E. (2006). Growth and reproduction in the Icelandic common seal (Phoca vitulina L., 1758). Marine Biology Research, 2(01), 59-73.

Khan, C. B., Markowitz, H., \& McCowan, B. (2006). Vocal development in captive harbor seal pups, Phoca vitulina richardii: Age, sex, and individual differences. The Journal of the Acoustical Society of America, 120(3), 1684-1694. https://doi.org/10.1121/1.2226530

Kooyman, G., \& Andersen, H. (1969). Deep diving. The Biology of Marine Mammals, 65-94.

Koren, L., \& Geffen, E. (2009). Androgens and social status in female rock hyraxes. Animal Behaviour, 77(1), 233238.

Kuester, J., Paul, A., \& Arnemann, J. (1995). Age-related and individual differences of reproductive success in male and female barbary macaques (Macaca sylvanus). Primates, 36(4), 461-476.

Le Boeuf, B. J. (1991). Pinniped mating systems on land, ice and in the water: Emphasis on the Phocidae. In The Behaviour of Pinnipeds (pp. 45-65). Springer Netherlands. https://doi.org/10.1007/978-94-011-3100-1_2 1-3, pp. 332-343). Elsevier Inc. https://doi.org/10.1016/B978-012370877-9.00045-1

Markussen, N. H., Bjørge, A., \& Øritsland, N. A. (1989). Growth in harbour seals (Phoca vitulina) on the Norwegian coast. Journal of Zoology, 219(3), 433-440.

Martin, K., Tucker, M. A., \& Rogers, T. L. (2017). Does size matter? Examining the drivers of mammalian vocalizations. Evolution, 71(2), 249-260. https://doi.org/10.1111/evo.13128

Neumann, D. R. (1999). Agonistic behavior in harbor seals (Phoca vitulina) in relation to the availability of haul-out space. Marine Mammal Science, 15(2), 507-525.

Osinga, N., Nussbaum, S. B., Brakefield, P. M., \& de Haes, H. A. U. (2012). Response of common seals (Phoca vitulina) to human disturbances in the Dollard estuary of the Wadden Sea. Mammalian Biology, 77(4), 281-287. https://doi.org/10.1016/j.mambio.2012.02.005 
Perry, E. A., \& Renouf, D. (1988). Further studies of the role of harbour seal (Phoca vitulina) pup vocalizations in preventing separation of mother-pup pairs. Canadian Journal of Zoology, 66(4), 934-938. https://doi.org/10.1139/z88-138

Pfefferle, D., \& Fischer, J. (2006). Sounds and size: identification of acoustic variables that reflect body size in hamadryas baboons, Papio hamadryas. Animal Behaviour, 72(1), 43-51.

Pfefferle, D., West, P. M., Grinnell, J., Packer, C., \& Fischer, J. (2007). Do acoustic features of lion, Panthera leo, roars reflect sex and male condition? The Journal of the Acoustical Society of America, 121(6), 3947. https://doi.org/10.1121/1.2722507

Plotsky, K., Rendall, D., Riede, T., \& Chase, K. (2013). Radiographic analysis of vocal tract length and its relation to overall body size in two canid species. Journal of Zoology, 291(1), 76-86. https://doi.org/10.1111/jzo.12048

Poole, J. H. (1999). Signals and assessment in African elephants: Evidence from playback experiments. Animal Behaviour, 58(1), 185-193. https://doi.org/10.1006/anbe.1999.1117

R Core Team (2013). R: A language and environment for statistical computing. R Foundation for Statistical Computing, Vienna, Austria. ISBN 3-900051-07-0, URL http://www.R-project.org/.

Ralls, K., Fiorelli, P., \& Gish, S. (1985). Vocalizations and vocal mimicry in captive harbor seals, Phoca vitulina. Canadian Journal of Zoology, 63(5), 1050-1056. https://doi.org/10.1139/z85-157

Ravignani, A., Fitch, W. T., Hanke, F. D., Heinrich, T., Hurgitsch, B., Kotz, S. A., ... de Boer, B. (2016). What pinnipeds have to say about human speech, music, and the evolution of rhythm. Frontiers in Neuroscience, 10, 274. https://doi.org/10.3389/fnins.2016.00274

Ravignani, A., \& Garcia, M. (2021). A cross-species framework to identify vocal learning abilities in mammals. Philosophical Transactions of the Royal Society B: Biological Sciences. 376, 20200394. https://doi.org/10.1098/rstb.2020.0394

Ravignani, A., Gross, S., Garcia, M., Rubio-Garcia, A., \& De Boer, B. (2017). How small could a pup sound? The physical bases of signaling body size in harbor seals. Current Zoology, 63(4), 457-465.

Reby, D., \& McComb, K. (2003). Anatomical constraints generate honesty: Acoustic cues to age and weight in the roars of red deer stags. Animal Behaviour, 65(3), 519-530. https://doi.org/10.1006/anbe.2003.2078

Reidenberg, J. S., \& Laitman, J. T. (2010). Generation of sound in marine mammals. In Handbook of Behavioral Neuroscience (Vol. 19, pp. 451-465). Elsevier. https://doi.org/10.1016/B978-0-12-374593-4.00041-3

Reijnders, P. J. H., Brasseur, S. M. J. M., \& Meesters, E. H. W. G. (2010). Earlier pupping in harbour seals, Phoca vitulina. Biology Letters, 6(6), 854-857. https://doi.org/10.1098/rsbl.2010.0468

Renouf, D. (1984). The vocalization of the Harbour seal pup (Phoca vitulina) and its role in the maintenance of contact with the mother. Journal of Zoology, 202(4), 583-590. https://doi.org/10.1111/j.14697998.1984.tb05055.x

Renouf, D. (2012). The behaviour of pinnipeds. Springer Science \& Business Media.

de Reus, K. (2017). Talking seals: vocal development in Eastern Atlantic harbour seal pups (Phoca vitulina vitulina). MSc Thesis, Royal Veterinary College, University of London.

de Reus, K., Jadoul, Y., \& Ravignani, A. (in prep.). Vocal development in Eastern Atlantic harbour seal pups (Phoca vitulina vitulina). 
Roers, F., Mürbe, D., \& Sundberg, J. (2009). Predicted singers' vocal fold lengths and voice classification—a study of x-ray morphological measures. Journal of Voice, 23(4), 408-413.

Sauvé, C., Beauplet, G., Hammill, M., \& Charrier, I. (2015). Acoustic analysis of airborne, underwater, and amphibious mother attraction calls by wild harbor seal pups (Phoca vitulina). Journal of Mammalogy, 96(3), 591-602.

Schneider, R. (1962). Vergleichende untersuchungen am kehlkopf der robben (mammalia, carnivora, pinnipedia). Gegenbaurs Morph Jb, 103, 177-262.

Taylor, A. M., \& Reby, D. (2010). The contribution of source-filter theory to mammal vocal communication research. Journal of Zoology, 280(3), 221-236.

Tyack, P., \& Miller, E. (2002). Vocal anatomy, acoustic communication and echolocation. In Marine mammal biology: An evolutionary approach (pp. 142-184). Oxford: Wiley-Blackwell.

Van den Berg, J., Zantema, J. T., \& Doornenbal, P. (1957). On the Air Resistance and the Bernoulli Effect of the Human Larynx. The Journal of the Acoustical Society of America, 29(5), 626-631. https://doi.org/10.1121/1.1908987

Van Parijs, S. M., \& Kovacs, K. M. (2002). In-air and underwater vocalizations of eastern Canadian harbour seals, Phoca vitulina. Canadian Journal of Zoology, 80(7), 1173-1179. https://doi.org/10.1139/z02-088

Vignal, C., \& Kelley, D. (2007). Significance of temporal and spectral acoustic cues for sexual recognition in Xenopus laevis. Proceedings of the Royal Society B: Biological Sciences, 274(1609), 479-488. https://doi.org/10.1098/rspb.2006.3744

Wyman, M., Mooring, M., McCowan, B., Penedo, M., \& Hart, L. (2008). Amplitude of bison bellows reflects male quality, physical condition and motivation. Animal Behaviour, 76(5), 1625-1639. 
$\underline{\text { Supplementary material (Appendix) }}$

\begin{tabular}{|c|c|c|c|c|c|c|c|}
\hline ID & $\begin{array}{l}\text { Age } \\
\text { class }\end{array}$ & $\begin{array}{l}\text { Where } \\
\text { from }\end{array}$ & Sex & $\begin{array}{c}\text { Length } \\
(\mathrm{cm})\end{array}$ & $\begin{array}{c}\text { Weight } \\
\text { (kg) }\end{array}$ & $\begin{array}{c}\text { Girth } \\
(\mathrm{cm})\end{array}$ & Cause of death \\
\hline 1 & weaner & NL & $\mathrm{F}$ & 86 & 15.6 & 90 & Euthanised \\
\hline 2 & weaner & NL & $\mathrm{F}$ & 99 & 17.3 & 83 & Died during rehab \\
\hline 3 & weaner & NL & M & 96 & 26.8 & 76 & Found dead in the wild \\
\hline 4 & weaner & NL & M & 96 & 22.9 & 71 & Euthanised \\
\hline 5 & weaner & NL & M & 86 & 19.2 & 71 & Died before rehab \\
\hline 6 & weaner & NL & M & 84 & 18.2 & 69 & Euthanised \\
\hline 7 & weaner & NL & M & 89 & 19.9 & 66 & Euthanised \\
\hline 8 & weaner & NL & $\mathrm{F}$ & 94 & 14.2 & 66 & Euthanised \\
\hline 9 & weaner & NL & $\mathrm{F}$ & 92 & 15.8 & 65 & Euthanised \\
\hline 10 & weaner & NL & $\mathrm{F}$ & 94 & 14.9 & 65 & Died during rehab \\
\hline 11 & weaner & NL & M & 104 & 20.8 & 64 & Died before rehab \\
\hline 12 & weaner & NL & $\mathrm{F}$ & 86 & 16.5 & 63 & Died during rehab \\
\hline 13 & weaner & NL & $\mathrm{F}$ & 86 & 15.7 & 63 & Euthanised \\
\hline 14 & weaner & NL & M & 100 & 18.37 & 62 & Euthanised \\
\hline 15 & weaner & NL & $\mathrm{F}$ & 93 & 16.8 & 62 & Euthanised \\
\hline 16 & weaner & NL & M & 114 & 18.8 & 61 & Died before rehab \\
\hline 17 & weaner & NL & $\mathrm{F}$ & 87 & 15.8 & 61 & Euthanised \\
\hline 18 & weaner & NL & $\mathrm{F}$ & 93 & 17.8 & 60.5 & Euthanised \\
\hline 19 & weaner & NL & M & 96 & 16.3 & 60 & Died during rehab \\
\hline 20 & weaner & NL & $\mathrm{F}$ & 82 & 15.3 & 60 & Euthanised \\
\hline 21 & weaner & NL & M & 80 & 14.3 & 60 & Died before rehab \\
\hline 22 & weaner & NL & $\mathrm{F}$ & 88 & 16.1 & 59 & Died during rehab \\
\hline 23 & weaner & NL & $\mathrm{F}$ & 89 & 16.9 & 58 & Euthanised \\
\hline 24 & weaner & NL & $\mathrm{F}$ & 71 & 10 & 58 & Euthanised \\
\hline 25 & weaner & NL & M & 92 & 17 & 57 & Euthanised \\
\hline 26 & weaner & NL & $\mathrm{F}$ & 94 & 14.5 & 57 & Died during rehab \\
\hline 27 & weaner & NL & M & 86 & 13.9 & 57 & Died before rehab \\
\hline 28 & weaner & NL & $\mathrm{F}$ & 79 & 11.9 & 56.5 & Euthanised \\
\hline 29 & weaner & NL & M & 85 & 14.6 & 56 & Died during rehab \\
\hline 30 & weaner & NL & M & 94 & 14.6 & 55 & Euthanised \\
\hline 31 & weaner & NL & $\mathrm{F}$ & 92 & 13.7 & 55 & Died during rehab \\
\hline 32 & weaner & NL & M & 80 & 13.1 & 55 & Died during rehab \\
\hline
\end{tabular}




\begin{tabular}{|c|c|c|c|c|c|c|c|}
\hline 33 & pup & NL & $\mathrm{F}$ & 75 & 11.9 & 55 & Euthanised \\
\hline 34 & pup & NL & M & 84 & 11.79 & 54 & Found dead in the wild \\
\hline 35 & weaner & NL & $\mathrm{F}$ & 93 & 14 & 53 & Died during rehab \\
\hline 36 & pup & NL & M & 83 & 11.47 & 52 & Euthanised \\
\hline 37 & weaner & NL & $\mathrm{F}$ & 93 & 13.9 & 51.5 & Euthanised \\
\hline 38 & weaner & NL & M & 86 & 13 & 51.5 & Died before rehab \\
\hline 39 & weaner & NL & $\mathrm{F}$ & 87 & 12.4 & 51 & Died before rehab \\
\hline 40 & pup & NL & M & 86 & 10.6 & 51 & Euthanised \\
\hline 41 & pup & NL & $\mathrm{F}$ & 81 & 11.37 & 49.5 & Euthanised \\
\hline 42 & pup & NL & $\mathrm{F}$ & 82 & 9.3 & 49 & Found dead in the wild \\
\hline 43 & pup & NL & M & 80 & 9.46 & 47 & Euthanised \\
\hline 44 & pup & NL & M & 73 & 8.6 & 46 & Found dead in the wild \\
\hline 45 & pup & NL & $\mathrm{F}$ & 77 & 8.5 & 44.5 & Died before rehab \\
\hline 46 & pup & NL & $\mathrm{F}$ & 80 & 9.63 & 44 & Found dead in the wild \\
\hline 47 & weaner & NL & M & 87 & 9.3 & 44 & Died during rehab \\
\hline 48 & pup & NL & $\mathrm{F}$ & 70 & 8 & 44 & Found dead in the wild \\
\hline 49 & pup & NL & M & 87 & 9.43 & 41 & Found dead in the wild \\
\hline 50 & weaner & NL & $\mathrm{F}$ & 77 & 7.47 & 40 & Euthanised \\
\hline 51 & pup & NL & M & 80 & 7.28 & 38.5 & Died during rehab \\
\hline 52 & pup & NL & M & 80 & 9.95 & 36 & Died before rehab \\
\hline 53 & weaner & $\mathrm{DE}$ & M & 85.5 & 19.2 & 67.5 & Mercy killed \\
\hline 54 & weaner & DE & $\mathrm{F}$ & 98.5 & 17 & 66 & Mercy killed \\
\hline 55 & weaner & $\mathrm{DE}$ & M & 90 & 14.6 & 65 & Mercy killed \\
\hline 56 & weaner & $\mathrm{DE}$ & M & 101 & 20.8 & 64 & Mercy killed \\
\hline 57 & weaner & DE & M & 90 & 17 & 63 & Found dead in the wild \\
\hline 58 & weaner & $\mathrm{DE}$ & $\mathrm{F}$ & 92 & 20.4 & 62 & Found dead in the wild \\
\hline 59 & weaner & $\mathrm{DE}$ & $\mathrm{F}$ & 99 & 17.8 & 60.5 & Mercy killed \\
\hline 60 & weaner & $\mathrm{DE}$ & M & 86 & 16 & 60.5 & Found dead in the wild \\
\hline 61 & weaner & $\mathrm{DE}$ & M & 90 & 16.6 & 59 & Found dead in the wild \\
\hline 62 & weaner & $\mathrm{DE}$ & $\mathrm{F}$ & 94 & 17 & 58 & Found dead in the wild \\
\hline 63 & weaner & $\mathrm{DE}$ & M & 90 & 14.6 & 57 & Mercy killed \\
\hline 64 & weaner & $\mathrm{DE}$ & M & 96 & 13.4 & 56 & Found dead in the wild \\
\hline 65 & weaner & $\mathrm{DE}$ & $\mathrm{F}$ & 82 & 11.6 & 55.5 & Found dead in the wild \\
\hline 66 & weaner & $\mathrm{DE}$ & $\mathrm{F}$ & 97 & 14.8 & 54 & Mercy killed \\
\hline 67 & weaner & $\mathrm{DE}$ & M & 81 & 10.2 & 51 & Mercy killed \\
\hline 68 & weaner & DE & $\mathrm{F}$ & 88.5 & 12 & 50 & Mercy killed \\
\hline
\end{tabular}


Table 2

690

691

Pairwise Spearman correlations for pups

692

\begin{tabular}{c|ccccccc} 
Variable & $\begin{array}{c}\text { Length } \\
(\mathrm{cm})\end{array}$ & $\begin{array}{c}\text { Weight } \\
(\mathrm{kg})\end{array}$ & $\begin{array}{c}\text { Girth } \\
(\mathrm{cm})\end{array}$ & $\begin{array}{c}\text { VTL } \\
(\mathrm{mm})\end{array}$ & $\begin{array}{c}\text { VFL } \\
(\mathrm{mm})\end{array}$ & $\begin{array}{c}\text { VFT } \\
(\mathrm{mm})\end{array}$ & $\begin{array}{c}\text { STAP1 } \\
(\mathrm{mm})\end{array}$ \\
\hline Weight $(\mathrm{kg})$ & 0.40 & & & & & \\
Girth $(\mathrm{cm})$ & 0.23 & 0.72 & & & & \\
VTL (mm) & 0.23 & -0.03 & -0.04 & & & \\
VFL (mm) & 0.22 & 0.08 & -0.01 & 0.49 & & & \\
VFT (mm) & -0.21 & 0.11 & 0.42 & 0.01 & 0.16 & & \\
STAP1 (mm) & 0.20 & 0.18 & 0.08 & 0.49 & $0.79 *$ & 0.55 & \\
STAP2 (mm) & 0.35 & 0.36 & 0.38 & 0.26 & 0.71 & 0.57 & $0.76^{*}$
\end{tabular}

694 Note. $*$ indicates $p<.05$ after correcting for multiple comparisons using the Holm-Bonferroni method.

695

696

697

698

699

700

Table 3

Pairwise Spearman correlations for weaners

$\begin{array}{cccccccc}\text { Variable } & \text { Length } & \text { Weight } & \text { Girth } & \text { VTL } & \text { VFL } & \text { VFT } & \text { STAP1 } \\ & (\mathrm{cm}) & (\mathrm{kg}) & (\mathrm{cm}) & (\mathrm{mm}) & (\mathrm{mm}) & (\mathrm{mm}) & (\mathrm{mm})\end{array}$

\begin{tabular}{c|cllllll}
\hline Weight $(\mathrm{kg})$ & $0.51^{*}$ & & & & & \\
Girth $(\mathrm{cm})$ & 0.28 & $0.76^{*}$ & & & & \\
VTL $(\mathrm{mm})$ & $0.39^{*}$ & $0.48^{*}$ & $0.39^{*}$ & & & \\
VFL $(\mathrm{mm})$ & $0.58^{*}$ & $0.64^{*}$ & $0.41^{*}$ & $0.54^{*}$ & & \\
VFT $(\mathrm{mm})$ & 0.16 & $0.48^{*}$ & $0.50^{*}$ & 0.22 & 0.34 & \\
STAP1 (mm) & $0.38^{*}$ & $0.61^{*}$ & $0.38^{*}$ & $0.46^{*}$ & $0.67^{*}$ & $0.47^{*}$ & \\
STAP2 (mm) & 0.32 & $0.48^{*}$ & 0.31 & $0.47^{*}$ & $0.57^{*}$ & 0.30 & $0.66^{*}$
\end{tabular}

701

702 Note. * indicates $p<.05$ after correcting for multiple comparisons using the Holm-Bonferroni method. 
Table 4

706

707

708

709

GLM estimates for vocal tract length (VTL)

710

Note. The reference level for Age Class is 'Pup' and the reference level for Sex is 'Female'.

711

712

713

Table 5

714

715

716

717

GLM estimates for vocal fold length (VFL)

\begin{tabular}{c|ccccc} 
Effect & Estimate & Std.Error & $2.5 \%$ & $97.5 \%$ & $\mathrm{p}$ \\
\hline Intercept & 42.4788 & 9.2445 & 23.9898 & 60.9678 & $<0.001$ \\
Age Class-Weaner & 4.6695 & 1.7801 & 1.1093 & 8.2297 & $<0.05$ \\
Length & 0.4170 & 0.1184 & 0.1802 & 0.6538 & $<0.001$ \\
Weight & 0.5933 & 0.2182 & 0.1569 & 1.0297 & $<0.01$ \\
Sex-Male & 40.7192 & 12.1685 & 16.3822 & 65.0562 & $<0.01$ \\
Length*Sex-Male & -0.4610 & 0.1379 & -0.7368 & -0.1852 & $<0.01$
\end{tabular}

718 Note. The reference level for Age Class is 'Pup' and the reference level for Sex is 'Female'.

\begin{tabular}{c|ccccc}
\multicolumn{1}{c}{ Effect } & Estimate & Std.Error & $2.5 \%$ & $97.5 \%$ & $\mathrm{p}$ \\
\hline Intercept & 9.1651 & 3.0598 & 3.0455 & 15.2847 & $<0.01$ \\
Age Class-Weaner & -2.7492 & 3.2348 & -9.2188 & 3.7204 & 0.399 \\
Length & -0.0189 & 0.0396 & -0.0981 & 0.0603 & 0.635 \\
Weight & 0.1050 & 0.0301 & 0.0448 & 0.1652 & $<0.001$ \\
Sex-Male & 1.0070 & 0.3670 & 0.2730 & 1.7410 & $<0.01$ \\
Age Class-Weaner*Length & 0.0562 & 0.0411 & -0.026 & 0.1384 & 0.177 \\
Age Class-Weaner*Sex-Male & -1.1833 & 0.4071 & -1.9975 & -0.3691 & $<0.01$
\end{tabular}


Table 6

GLM estimates for subglottic tracheal dorsoventral distance 1 (STDV1)

Note. The reference level for Age Class is 'Pup' and the reference level for Sex is 'Female'.

Table 7

731

\begin{tabular}{c|ccccc} 
Effect & Estimate & Std.Error & $2.5 \%$ & $97.5 \%$ & $\mathrm{p}$ \\
\hline Intercept & 15.389 & 1.6827 & 12.0236 & 18.7544 & $<0.001$ \\
Age Class-Weaner & 1.7474 & 0.4352 & 0.8770 & 2.6178 & $<0.001$ \\
Length & 0.0472 & 0.0236 & 0.0000 & 0.0944 & $<0.05$ \\
Weight & 0.1887 & 0.0533 & 0.0821 & 0.2953 & $<0.001$ \\
Sex-Male & 0.5956 & 0.2754 & 0.0448 & 1.1464 & $<0.05$
\end{tabular}

GLM estimates for subglottic tracheal dorsoventral distance 2 (STDV2)

\begin{tabular}{c|ccccc} 
Effect & Estimate & Std.Error & $2.5 \%$ & $97.5 \%$ & $\mathrm{p}$ \\
\hline Intercept & 9.9726 & 1.8526 & 6.2674 & 13.6778 & $<0.001$ \\
Age Class-Weaner & 1.5194 & 0.4792 & 0.5610 & 2.4778 & $<0.01$ \\
Length & 0.0427 & 0.0260 & -0.0093 & 0.0947 & 0.105 \\
Weight & 0.1560 & 0.0587 & 0.0386 & 0.2734 & $<0.01$ \\
Sex-Male & 0.4523 & 0.3032 & -0.1541 & 1.0587 & 0.141
\end{tabular}



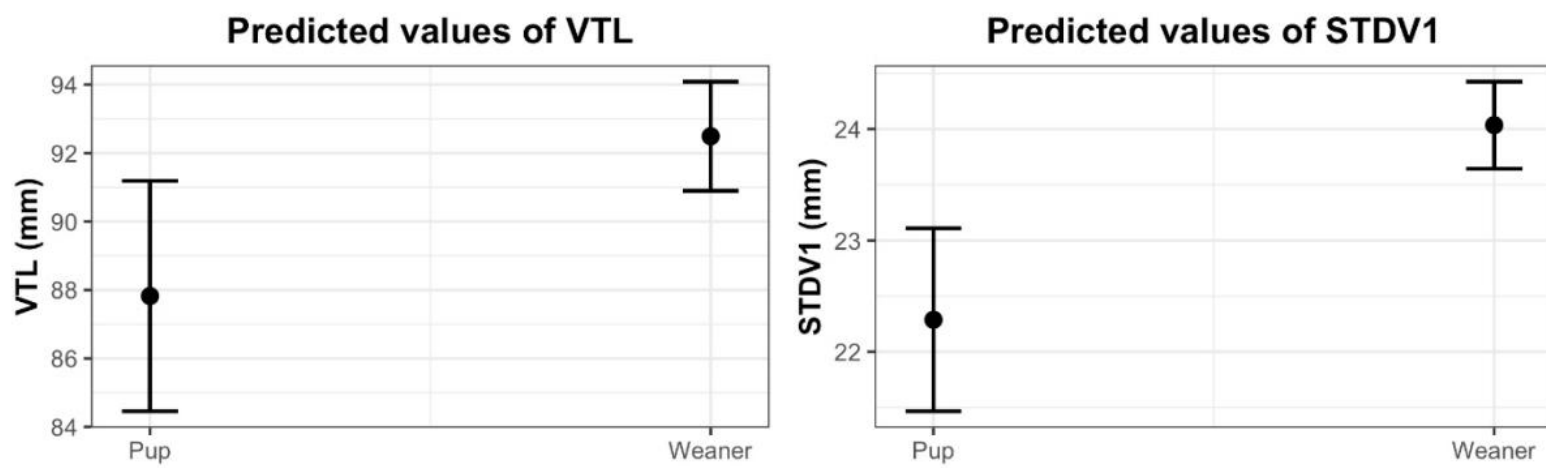

Predicted values of VFL
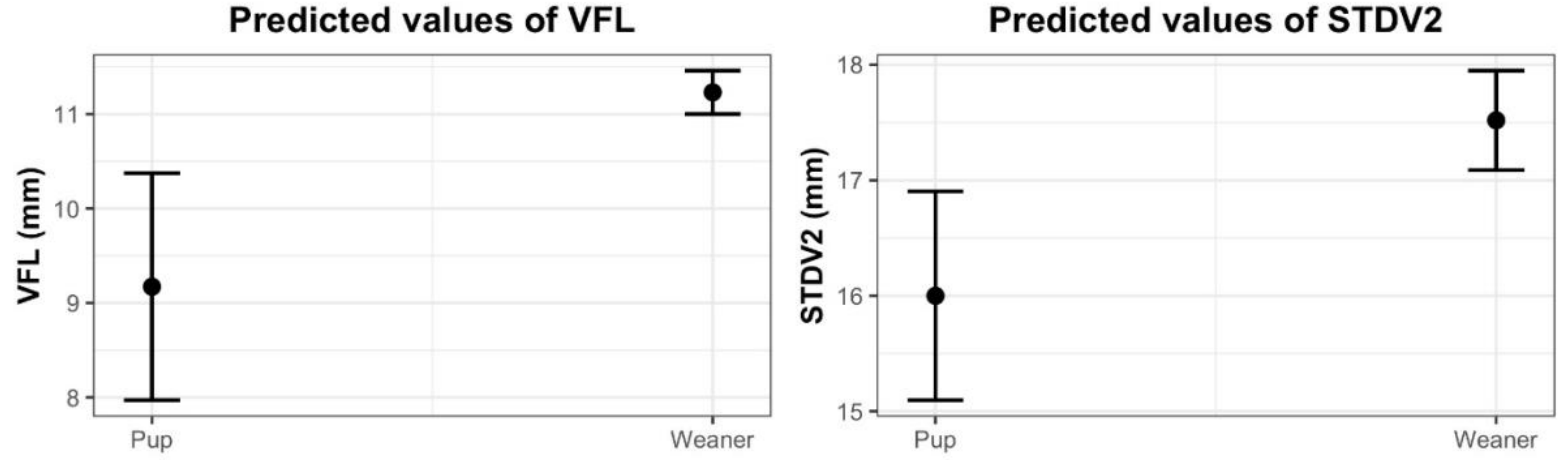

Figure 1. Predicted effects of age class (A) in each of the GLM models.
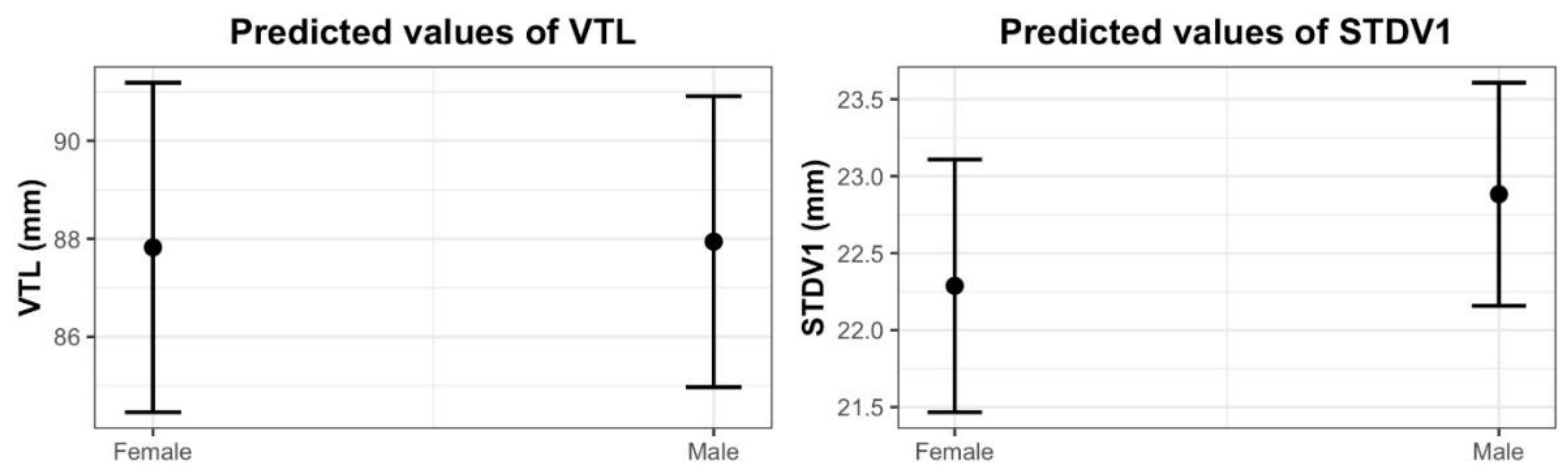

Predicted values of VFL
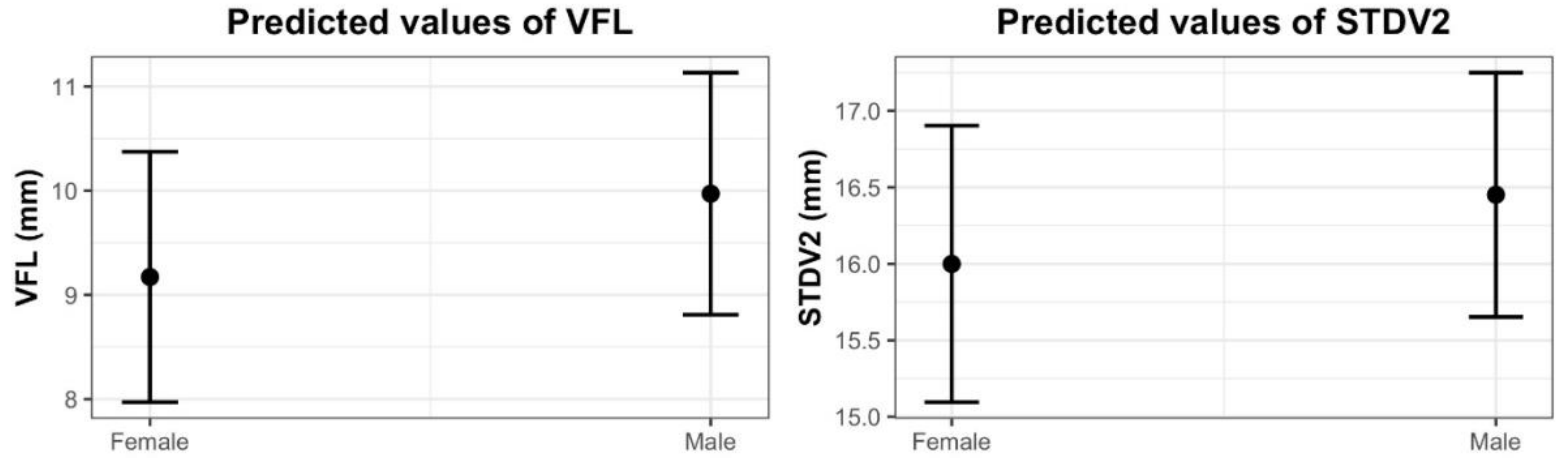

Figure 2. Predicted effects of sex (S) in each of the GLM models. 

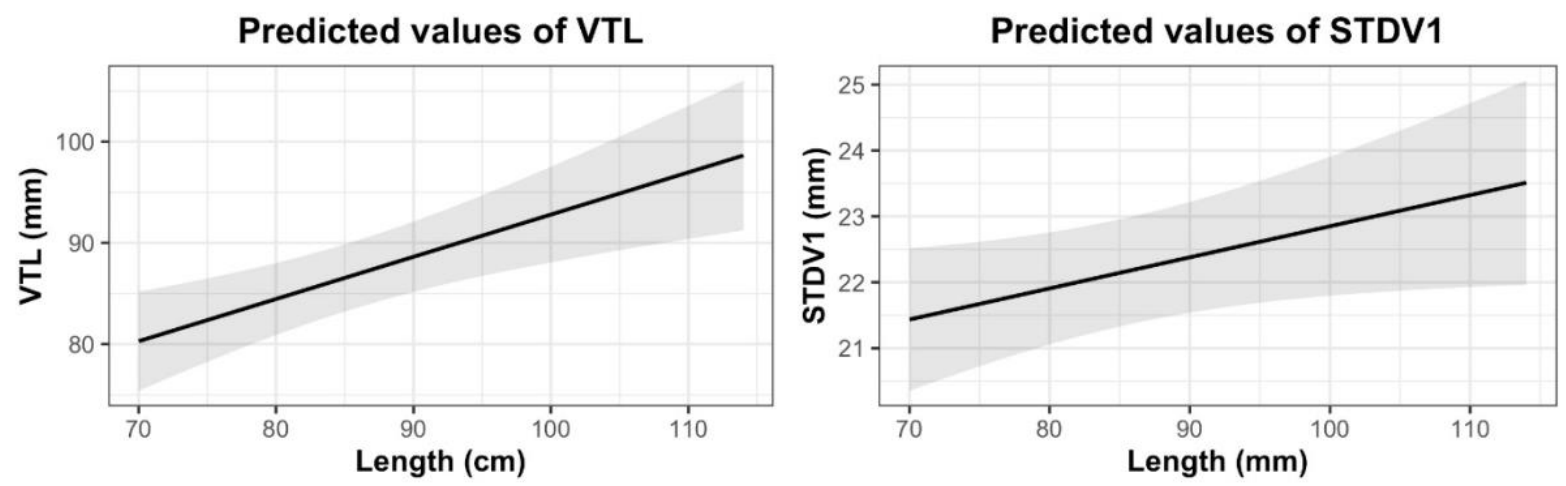

Predicted values of VFL
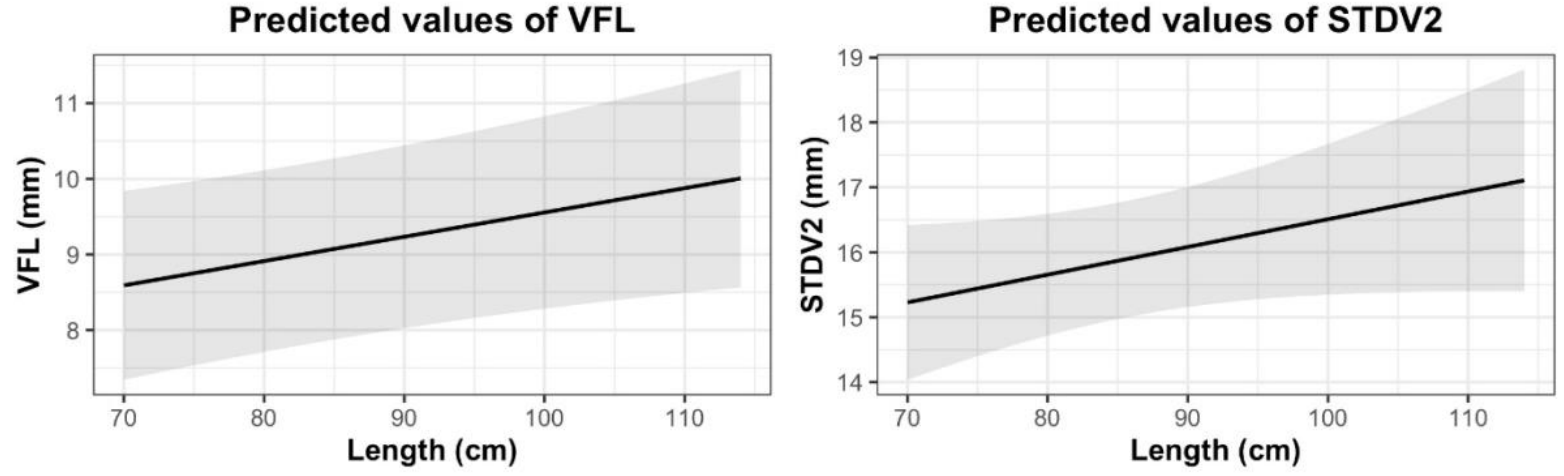

747

748

749

Figure 3. Predicted effects of length (L) in each of the GLM models.
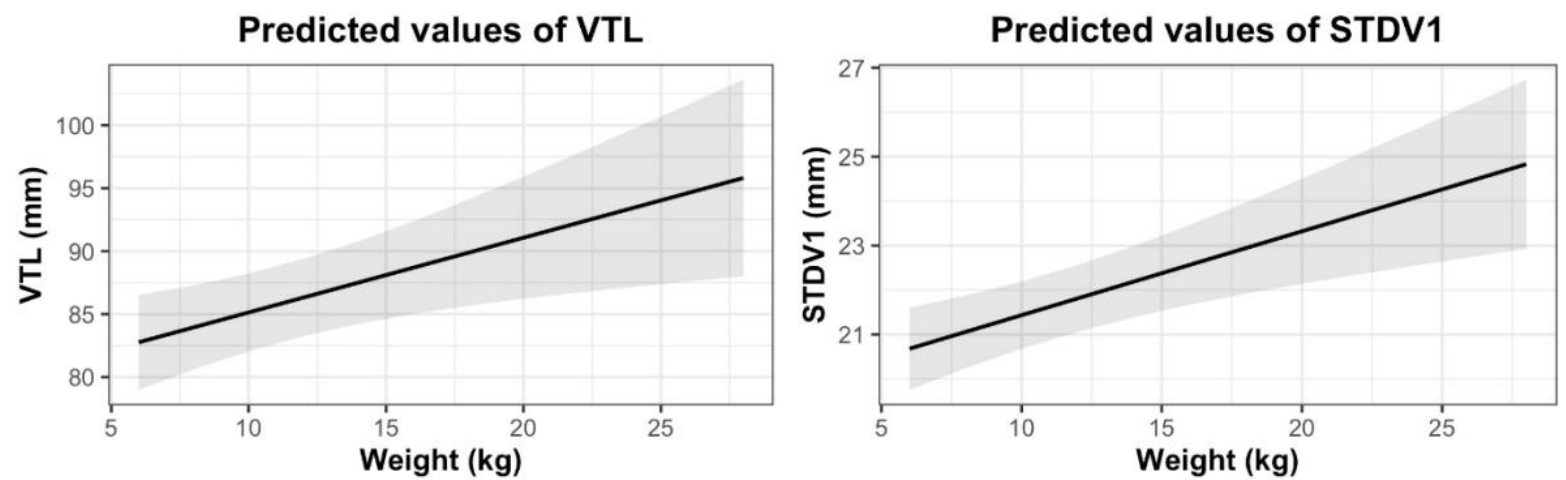

Predicted values of VFL
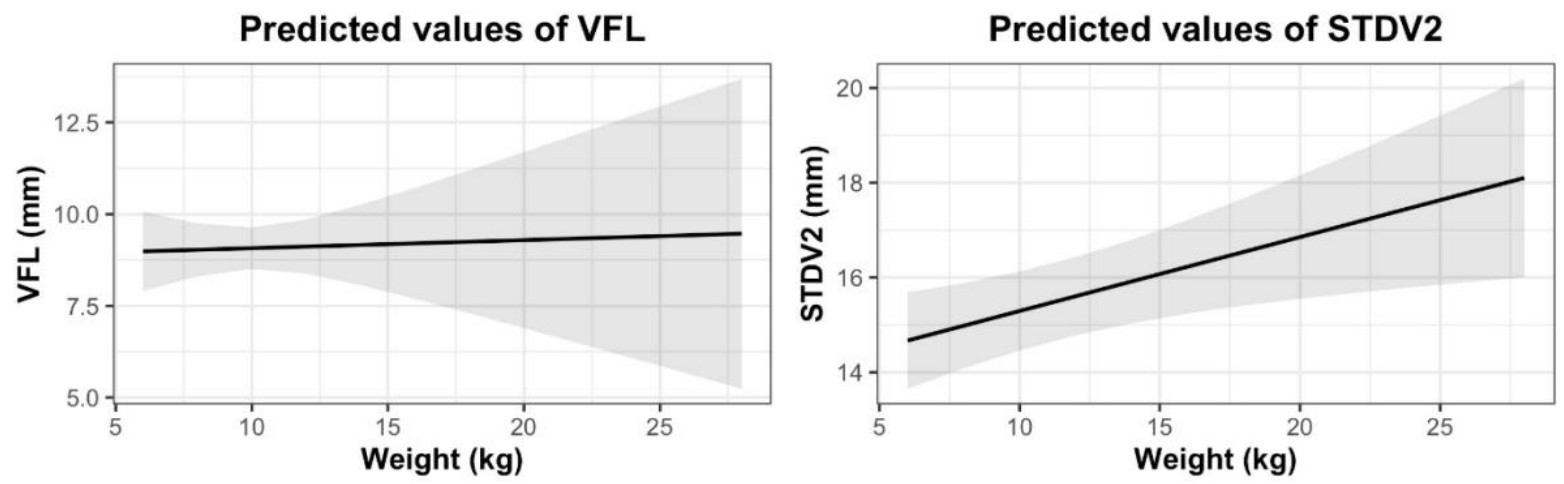

Figure 4. Predicted effects of weight (W) in each of the GLM models. 


\section{Predicted values of VTL}

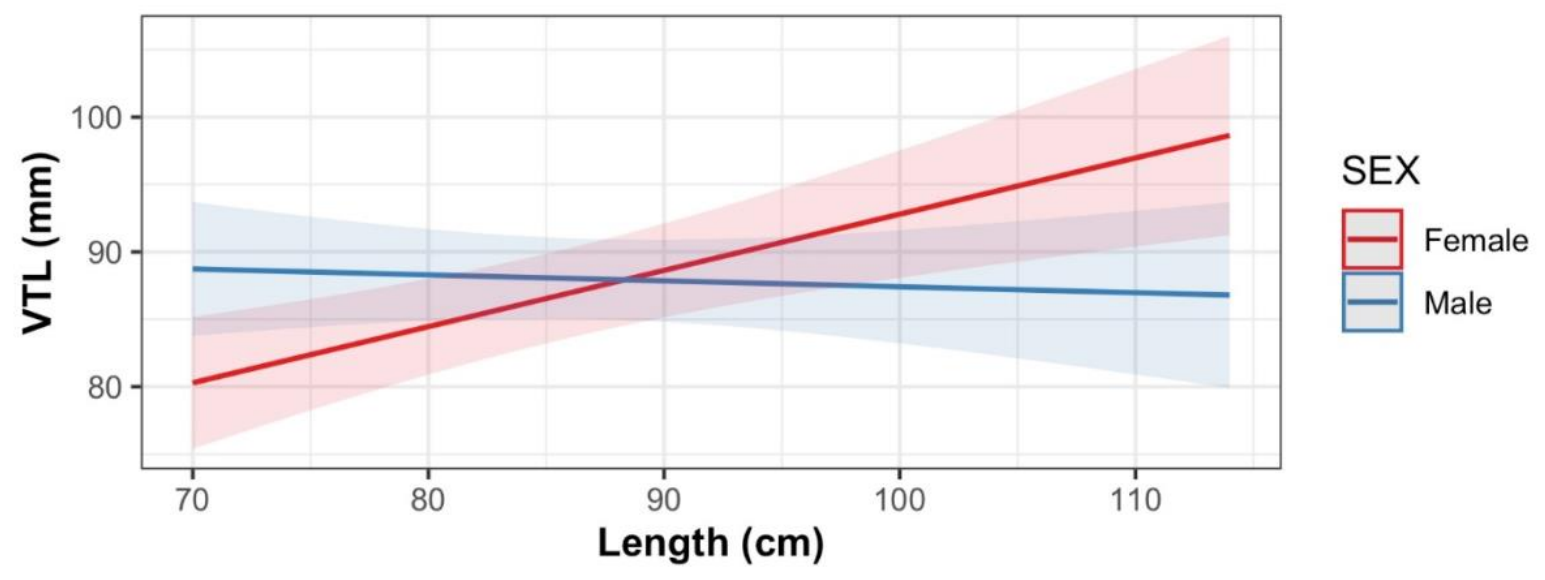

Predicted values of VFL

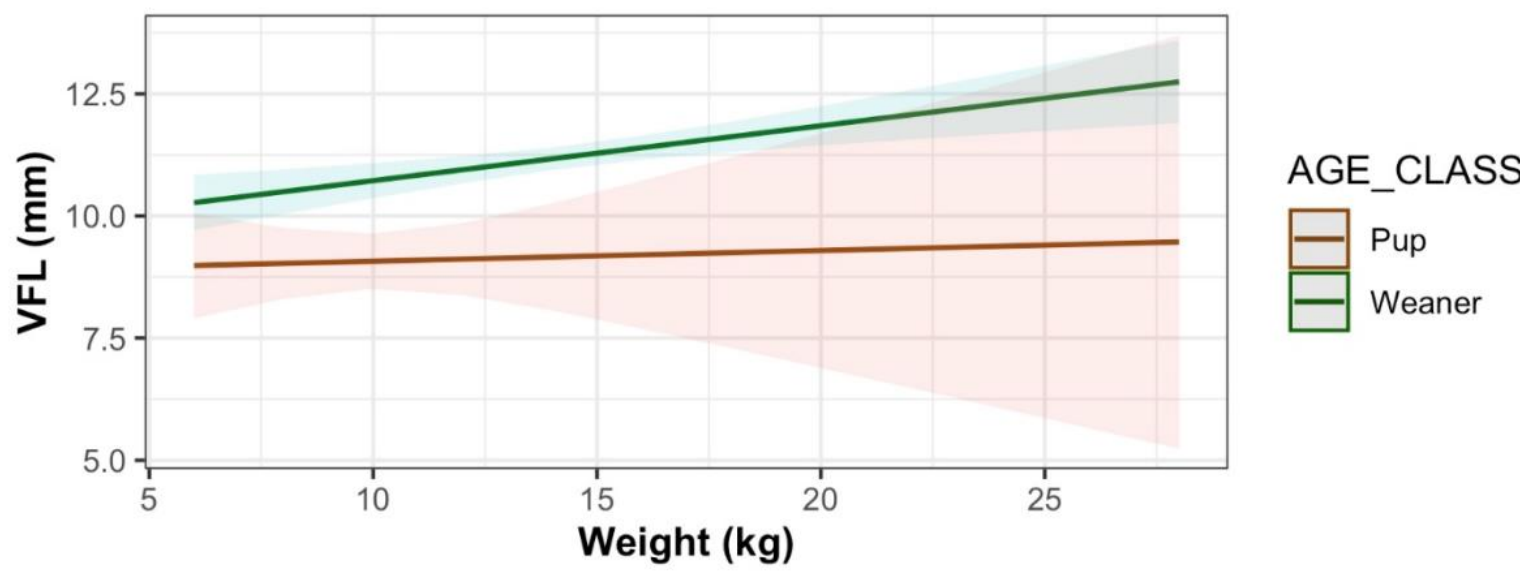

Predicted values of VFL

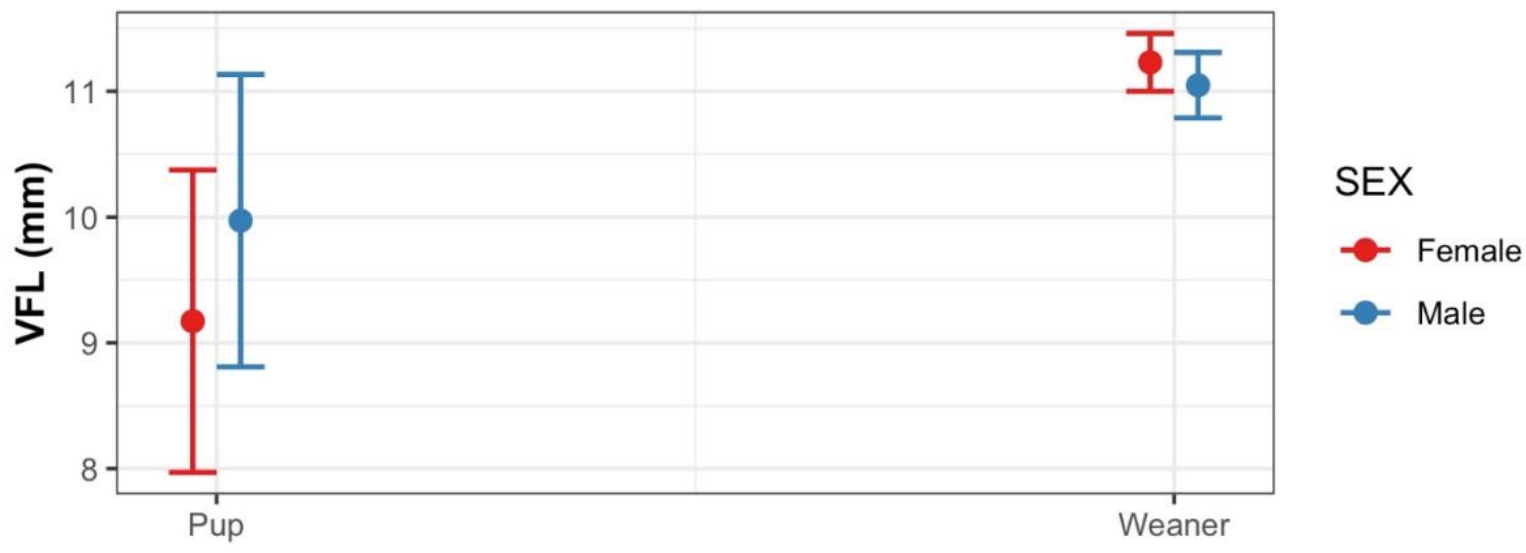

Figure 5. Predicted effects of the length and sex interaction for VTL (top), the weight and age interaction for VFL (middle) and the age and sex interaction for VFL (bottom). 